\title{
Greater morphological and primary metabolic adaptations in roots contribute to phosphate-deficiency tolerance in the bread wheat cultivar Kenong199
}

\author{
Lu Zheng ${ }^{1}$, Mohammad Rezaul Karim ${ }^{1,2}$, Yin-Gang Hü ${ }^{3}$, Renfang Shen ${ }^{1,2}$ and Ping Lan ${ }^{1,2^{*}}$
}

\begin{abstract}
Background: Phosphate (Pi) deficiency severely affects crop growth and productivity, including wheat, therefore it is necessary to develop cultivars with enhanced Pi-deficiency tolerance. However, the underlying mechanism of Pideficiency tolerance in wheat is still elusive. Two contrasting wheat cultivars, low-Pi tolerant Kenong199 (KN199) and low-Pi sensitive Chinese Spring (CS) were used to reveal adaptations in response to Pi deficiency at the morphological, physiological, metabolic, and molecular levels.

Results: KN199 was more tolerant to Pi deficiency than CS with significantly increased root biomass and R/S ratio. Root traits, the total root length, total root surface area, and total root volume, were remarkably enhanced by $\mathrm{Pi}$ deficiency in KN199. The shoot total P and soluble Pi concentrations of KN199 were significantly higher than those of CS, but not in roots. In KN199, high Pi level in shoots is a higher priority than that in roots under Pi deficiency. It was probably due to differentially regulation in the miR399-mediated signaling network between the shoots of the two cultivars. The Pi deficiency-induced root architecture adaptation in KN199 was attributed to the regulation of the hormone-mediated signaling (ethylene, gibberellin, and jasmonates). The expression of genes associated with root development and Pi uptake was enhanced in KN199. Some primary metabolites (amino acids and organic acids) were significantly accumulated in roots of KN199 under Pi deficiency.
\end{abstract}

Conclusions: The low-Pi tolerant wheat cultivar KN199 possessed greater morphological and primary metabolic adaptations in roots than CS under Pi deficiency. The adaption and the underlying molecular mechanisms in wheat provide a better understanding of the Pi-deficiency tolerance and the strategies for improving Pi efficiency in wheat.

Keywords: Phosphate deficiency, Wheat, Roots, Signaling, Metabolites

\section{Background}

Phosphorus (P) is an essential macronutrient required for plant growth and development. It is one of the main constituents of nucleic acids, phospholipids, ATP and

\footnotetext{
* Correspondence: plan@issas.ac.cn

${ }^{1}$ State Key Laboratory of Soil and Sustainable Agriculture, Institute of Soil Science, Chinese Academy of Sciences, Nanjing 210008, China ${ }^{2}$ University of Chinese Academy of Sciences, Beijing 100049, China Full list of author information is available at the end of the article
}

phosphorylated enzymes, and so on [1]. Phosphorus in plants is acquired from the soil mainly by uptake of inorganic phosphate $(\mathrm{Pi})$. However, $\mathrm{P}$ exists as various insoluble phosphate minerals or organic complexes and unevenly distributed in soils [2]. Compared with other macronutrients, $\mathrm{P}$ is the most immobile, inaccessible, and unavailable one. Low $\mathrm{Pi}$ availability is often a primary limiting factor for plant growth, development,

C C The Author(s). 2021 Open Access This article is licensed under a Creative Commons Attribution 4.0 International License, which permits use, sharing, adaptation, distribution and reproduction in any medium or format, as long as you give appropriate credit to the original author(s) and the source, provide a link to the Creative Commons licence, and indicate if changes were made. The images or other third party material in this article are included in the article's Creative Commons licence, unless indicated otherwise in a credit line to the material. If material is not included in the article's Creative Commons licence and your intended use is not permitted by statutory regulation or exceeds the permitted use, you will need to obtain permission directly from the copyright holder. To view a copy of this licence, visit http://creativecommons.org/licenses/by/4.0/ The Creative Commons Public Domain Dedication waiver (http://creativecommons.org/publicdomain/zero/1.0/) applies to the data made available in this article, unless otherwise stated in a credit line to the data. 
productivity, and grain quality in agricultural systems [3].

To adapt to low-Pi environments, plants have evolved several complex and elaborate responsive and adaptive mechanisms to maintain $\mathrm{Pi}$ homeostasis, including root system architecture (RSA) modification, organic acid exudation, production and secretion of phosphatases, and association of the roots with soil microbes, and so on [4, 5]. Meanwhile, plants modulate primary, secondary, and lipid metabolism for high Pi uptake and utilization efficiency. Among them, RSA is a crucial component for enhanced root exploration capacity and Pi uptake capacity due to low mobility and uneven distribution of $\mathrm{Pi}$ in soil [6]. Fine roots are shorter and more with high plasticity [7], and a rapid change in fine root production plays a major role in response to Pi deficiency $[8,9]$. The modification of root traits varies significantly across species and cultivars. In Arabidopsis thaliana ecotype Col-0, Pi starvation inhibited the primary root growth, but lateral roots and root hairs were increased [10]. Vejchasarn et al. tested 15 rice (Oryza sativa L.) genotypes and revealed that $\mathrm{Pi}$ deficiency significantly reduced large lateral root density and small and large lateral root length, and increased root hair length and density [11]. Wen et al. characterized root traits of 16 major herbaceous crop species and found crop species with thinner roots displayed a stronger response in root branching, first-order root length, and specific root length of the whole root system in response to limiting soil $\mathrm{Pi}$ [12]. The degree of plasticity and relative allocation of root length varied among genotypes. In wheat (Triticum aestivum), Pi deficiency modulated the branching distribution of root architecture from linear (evenly spaced branches) to exponential (a greater number of branches at the top of the soil) [13]. Moreover, da Silva et al. reported the Brazilian wheat cultivars with higher P uptake efficiency exhibited total root shallow, enhancing root proliferation in P-rich surface soil [14].

The adaptations to Pi starvation at morphological, biochemical, and physiological levels first contributed to local and systemic sensing and signaling systems [15, 16]. After changes of external Pi concentration, Pi itself, hormones, microRNAs, and sugars serve as signals to elicit transcriptional and posttranslational responses. miR399 is one of the best characterized and important microRNA-mediated P-signaling and well conversed in plants. The miR399 signaling pathway includes several key Pi deficiency responsive genes, phosphate starvation response 1 (PHR1) [17], induced by phosphate starvation 1 (IPS1), SPX (named after SYG1/PHO81/XPR1) [18], and PHOSPHATE 2 (PHO2). Among these genes, IPS1, a non-protein coding gene, includes a motif with sequence complementarity with miR399 in different plant species $[19,20]$. Besides, many hormones serve as $\mathrm{Pi}$ signaling components in developmental reprogramming, leading to changes in RSA [16], such as auxin [21], ethylene [22], gibberellin (GA) [23], and jasmonates (JAs). In Arabidopsis, local modifications of auxin concentration induced by low Pi availability involved in the lateral root development [21]; inhibition of ethylene production or action decreased root elongation under Pi deficiency [24]. Transcript levels of genes involved in hormone production, sensitivity, and transport were regulated under Pi stress [25]. The metabolic changes are the ultimate reflection of gene expression. The metabolite profiling could provide a broader view for the final systematic adjustment [26-28]. Metabolomic analysis revealed Pi deficiency led to increases of amino acids, ammonium metabolites, and di- and tri-saccharides, decreases of small $\mathrm{P}$-containing metabolites, and various changes of organic acids in the tricarboxylic acid (TCA) in barley [27], maize [28], common bean [29], and soybean [30]. These changes are the results of more efficient utilization of carbon, nitrogen, and $\mathrm{P}$ under low-Pi conditions.

Molecular mechanisms underlying Pi signaling, adaptation and metabolic changes were extensively studied in Arabidopsis and rice $[15,16,31,32]$. Wheat is one of the most economically important cereal crops in the world. The growth and yield of wheat are limited to low $\mathrm{P}$ availability in soil [33]. Thus, $\mathrm{P}$ fertilizers are widely and continuously applied in agricultural production system. The consumption of chemical P fertilizers in China had increased approximately 100-fold, from $0.05 \mathrm{Mt}$ in 1960 to $5.3 \mathrm{Mt}$ in 2010 [34]. In addition, the excessive application of $\mathrm{P}$ fertilizer causes eutrophication and toxic algal blooms in aquatic ecosystems [35]. The accumulation of $\mathrm{P}$ annually in the fields of wheat was $29.4 \mathrm{~kg}$ $\mathrm{ha}^{-1}$, which was much higher than those in rice and maize in China [36]. So, it is of great importance to improve low-Pi tolerance and Pi efficiency of wheat for practical food security and agricultural sustainability. Due to the complexity of the hexaploid genome, the related studies in wheat are few and lagging compared with its importance in food crops. The morphological, metabolic, and molecular mechanisms of wheat in response to phosphorus deficiency remained to be elucidated.

China is the world's largest wheat producer in the last 20 years (110 million metric tonners per year from 1994 to 2016, data obtained from FAO). The average wheat yield in China was steadily increasing from $3.43 \mathrm{t} / \mathrm{ha}$ in 1994 to $5.41 \mathrm{t} / \mathrm{ha}$ in 2016 . It partly contributed to the breeding and popularization of new cultivars with good qualities, stress tolerances, and high yield. Among them, Kenong199 (KN199) was one of the main cultivated wheat cultivars in the northern region of the HuangHuai winter wheat production base for many years with 
high nitrogen and $\mathrm{P}$ stress resistance and grain yield [37]. In the field experiment, KN199 displayed high tillering capacity, spike formation, and grain production under low P input [38]. However, its underlying mechanism of the low-Pi tolerance of KN199 is still unclear to us. Chinese Spring (CS) exhibited low P uptake, utilization efficiency efficiencies, and grain production under P stress in the field experiment [39]. In this study, we demonstrated the morphological, physiological, metabolic, and molecular characteristics of KN199 in response to Pi deficiency by comparing them with CS. Our results revealed that under Pi deficiency the low-Pi tolerant KN199 had higher Pi and P concentrations in shoots, greater increased root biomass and fine root length, and accumulated higher content of organic acids in TCA cycle and branched chain amino acids in roots than CS. We also provided molecular characteristics for these adaptions for better understanding the mechanisms of low-Pi tolerance in wheat.

\section{Results}

KN199 was more tolerant to Pi deficiency than CS with significantly increased root biomass and $\mathrm{R} / \mathrm{S}$ ratio

To elucidate the low-Pi tolerance mechanism, the effect of Pi deficiency on the two contrasting cultivars, CS and KN199, was investigated at the seedling stage growing under hydroponic condition. The growth of low-Pi sensitive cultivar CS was seriously inhibited after 7 days of $\mathrm{Pi}$ deficiency treatment. Compared with Pi-sufficient $(+\mathrm{Pi})$ condition, the shoot fresh weight $(\mathrm{FW})$ of $\mathrm{CS}$ was dramatically decreased by $39 \%$ under Pi-deficient $(-\mathrm{Pi})$ condition, while the shoot FW of low-Pi tolerant cultivar KN199 was not significantly affected (Fig. 1, a). Conversely, the root FWs of the two cultivars were both significantly increased under Pi deficiency (Fig. 1, b).
Moreover, the increase of root FW in KN199 was much higher than that in CS (27 and 58\% increase in CS and KN199, respectively). Under - Pi condition, the FW of KN199 was lower than that of CS, so the R/S ratio (FW) of KN199 was higher than that of CS (Fig. 1, c). The R/S ratios were significantly increased by Pi deficiency treatment in both cultivars. Moreover, the R/S ratio of KN199 under Pi deficiency reached the highest value. The root and shoot dry weight (DW) had a similar tendency with these determined by FW (Table 1). The shoot heights of two cultivars were both inhibited by $\mathrm{Pi}$ deficiency, but not significantly. Reversely, the root lengths under Pi deficiency were both longer than these under $+\mathrm{Pi}$ condition. Remarkably, the increase of root length was significant in KN199, but not in CS (Table 1). In short, compared to the low-Pi sensitive cultivar CS, KN199 was more tolerant to Pi deficiency with drastically increased root biomass and R/S ratio.

\section{KN199 had great adaptation in root architecture under Pi deficiency}

For the massive increase of wheat root biomass in response to Pi deficiency, the global root architecture of the two cultivars was further analyzed. Pi deficiency induced the root growth, which was much more apparent in KN199 than that in CS (Fig. 2). After Pi deficiency treatment, the total root length and total root surface area of KN199 significantly increased by 44 and 39\%, respectively (Table 2). Fine root represents about $88 \%$ of the total root length in two cultivars. Thick root length slightly increased in two cultivars, however not significantly. However, the fine root length of KN199 was significantly increased by $44 \%$, which only $11 \%$ in CS. Thus, fine roots contributed to the increase of the total root length of KN199 in response to Pi stress. And the
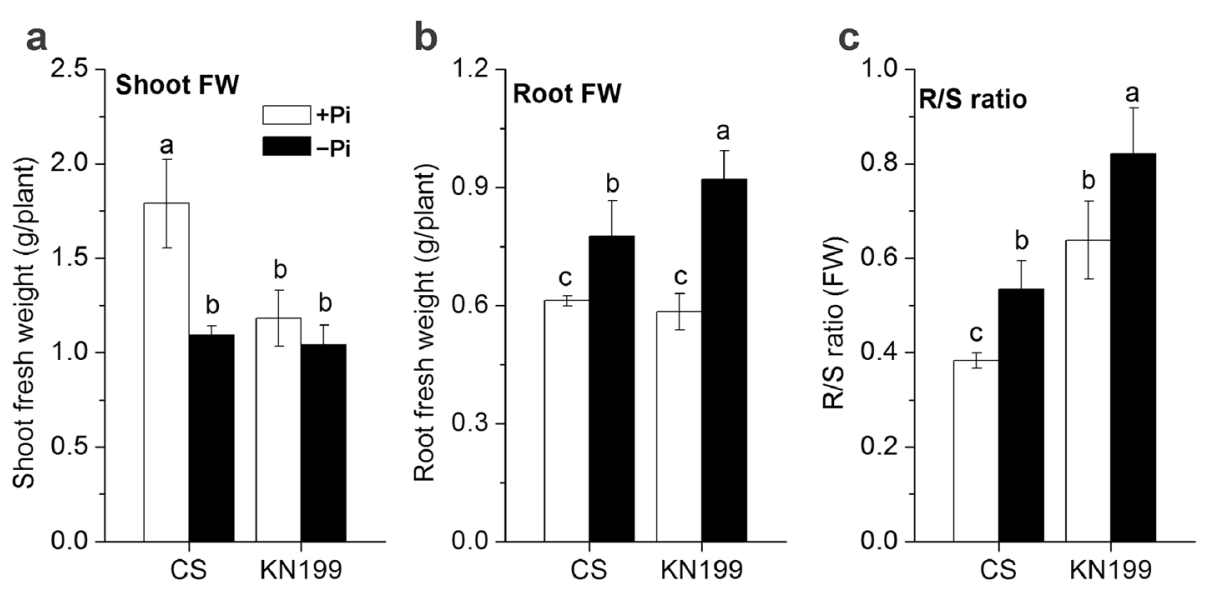

Fig. 1 Effect of Pi deficiency on the shoot and root of two wheat cultivars. a Shoot fresh weight (FW), b root FW, and c R/S ratio (FW). Twelveday-old wheat seedlings were grown on Pi-sufficient (+Pi, white bars) or Pi-deficient (-Pi, black bars) solution for 7 days. Data are means \pm SD ( $n$ $=4$ ). Different lowercase letters indicate significant differences at $p<0.05$ among columns using the least significant difference multiple range test 
Table 1 Growth, phosphate uptake, and phosphate utilization efficiency of the two cultivars under Pi deficiency

\begin{tabular}{|c|c|c|c|c|c|}
\hline \multirow[t]{2}{*}{ Traits $^{a}$} & \multirow[t]{2}{*}{ Tissues } & \multicolumn{2}{|c|}{ Chinese Spring (CS) } & \multicolumn{2}{|c|}{ Kenong199 (KN199) } \\
\hline & & $+\mathrm{Pi}$ & $-\mathrm{Pi}$ & $\overline{+P i}$ & $-\mathrm{Pi}$ \\
\hline \multirow[t]{3}{*}{ Biomass (mg DW } & Shoot & $252.7 \pm 40.1 \mathrm{a}$ & $207.4 \pm 27.1 b$ & $171.2 \pm 5.0 \mathrm{~b}$ & $158.9 \pm 18.5 b$ \\
\hline & Root & $43.8 \pm 5.8 b c$ & $49.2 \pm 3.6 a b$ & $36.9 \pm 2.0 c$ & $53.3 \pm 7.7 a$ \\
\hline & $R / S$ & $0.207 \pm 0.017 b$ & $0.266 \pm 0.010 \mathrm{ab}$ & $0.236 \pm 0.026 \mathrm{ab}$ & $0.298 \pm 0.078 a$ \\
\hline \multirow[t]{2}{*}{ Length $(\mathrm{cm})$} & Shoot & $35.7 \pm 1.9 a$ & $32.8 \pm 2.0 \mathrm{a}$ & $28.2 \pm 2.7 b$ & $27.7 \pm 3.8 b$ \\
\hline & Root & $32.6 \pm 1.9 c$ & $33.6 \pm 3.7 b c$ & $34.9 \pm 2.9 b$ & $38.9 \pm 1.8 \mathrm{a}$ \\
\hline \multirow[t]{2}{*}{ Total P conc. (mg P/g DW) } & Shoot & $4.60 \pm 0.69 b$ & $1.21 \pm 0.10 \mathrm{~d}$ & $6.31 \pm 0.73 a$ & $2.12 \pm 0.16 c$ \\
\hline & Root & $6.46 \pm 0.15 b$ & $2.52 \pm 0.26 c$ & $7.99 \pm 0.37 a$ & $2.81 \pm 0.13 c$ \\
\hline \multirow[t]{2}{*}{ Soluble Pi conc. (ug P/g FW'd) } & Shoot & $282.40 \pm 33.44 b$ & $81.31 \pm 0.83 d$ & $449.72 \pm 18.81 a$ & $146.07 \pm 18.30 c$ \\
\hline & Root & $198.39 \pm 36.61 b$ & $43.68 \pm 6.46 c$ & $290.73 \pm 40.95 a$ & $58.10 \pm 10.28 c$ \\
\hline \multirow[t]{2}{*}{ P content (mg P/plant) } & Shoot & $1.78 \pm 0.22 \mathrm{a}$ & $0.38 \pm 0.03 c$ & $1.26 \pm 0.27 b$ & $0.45 \pm 0.88 c$ \\
\hline & Root & $0.55 \pm 0.04 a$ & $0.18 \pm 0.03 b$ & $0.50 \pm 0.13 a$ & $0.20 \pm 0.10 b$ \\
\hline \multirow[t]{2}{*}{ PUE (g DW/mg P) } & Shoot & $0.57 \pm 0.06 c$ & $2.68 \pm 0.22 \mathrm{a}$ & $0.82 \pm 0.16 c$ & $2.27 \pm 0.36 b$ \\
\hline & Root & $1.81 \pm 0.14 b$ & $5.52 \pm 0.78 a$ & $2.09 \pm 0.48 b$ & $4.92 \pm 0.28 a$ \\
\hline
\end{tabular}

Notes: ${ }^{a}$ 12-day-old wheat seedlings were grown on Pi-sufficient (+Pi) solution or Pi-deficient (-Pi) solutions for 7 days. Data are means \pm SD ( $\left.n=4\right)$, and different letters indicate significant differences using the least significant difference multiple range test $(p<0.05)$. ${ }^{b}$ DW: dry weight; ${ }^{c}$ conc.: concentration; ${ }^{d}$ FW: fresh weight; ${ }^{e}$ PUE: phosphate utilization efficiency

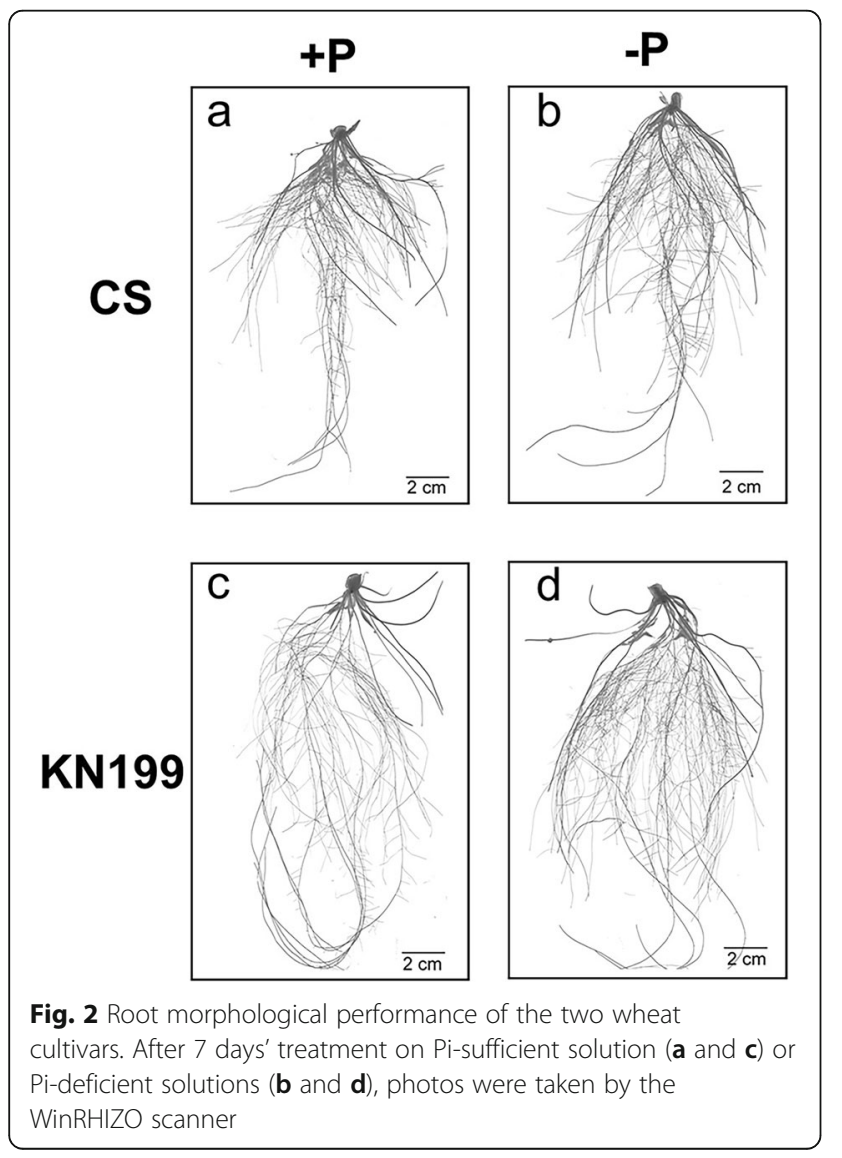

total root volume also increased by $33 \%$. The increases of these traits induced by Pi deficiency in CS were much less than those of KN199, and not significant. The average diameter of roots did not significantly change in the two cultivars. The number of root tips significantly increased in CS under Pi deficiency, but only significantly in KN199. Thus, the increase of root biomass in CS under Pi deficiency was mainly due to the increase of fine roots and root tip numbers; the enormous increase of root biomass in KN199 contributed to the enhancement of total root length (fine roots), total root surface area, and total root volume. Phosphorus is immobile in soils, so the fine root development with longer root length and greater root surface area is crucial for absorbing more Pi, particularly in the low-Pi environments.

\section{KN199 showed higher Pi concentrations in shoots than CS under Pi deficiency, but not in roots}

The P uptake and PUE in shoots and roots of the two wheat cultivars in response to Pi deficiency were displayed in Table 1 . Under $+\mathrm{Pi}$ and $-\mathrm{Pi}$ conditions, the shoot soluble Pi and total P concentrations of KN199 were all significantly higher than these of CS. Particularly, the shoot soluble Pi concentration in KN199 under -Pi was almost two folds higher than that in CS. But, these variations in roots were small. Under $+\mathrm{Pi}$ condition, KN199 still showed significantly higher levels of soluble $\mathrm{Pi}$ and total $\mathrm{P}$ concentrations in roots than these in CS. While under Pi deficiency, the two cultivars had no significant variations in the root soluble $\mathrm{Pi}$ and total $\mathrm{P}$ concentrations. For the high biomass of CS under $+\mathrm{Pi}$ condition, the shoot P content of KN199 was lower than 
Table 2 Phenotypic evaluation of global root morphology of the two wheat cultivars under Pi deficiency

\begin{tabular}{|c|c|c|c|c|}
\hline \multirow[t]{2}{*}{ Traits $^{a}$} & \multicolumn{2}{|l|}{ CS } & \multicolumn{2}{|l|}{ KN199 } \\
\hline & $+\mathrm{Pi}$ & $-\mathrm{Pi}$ & $+\mathrm{Pi}$ & $-\mathrm{Pi}$ \\
\hline Total root length $(\mathrm{cm})$ & $361 \pm 40 b$ & $411 \pm 42 b$ & $362 \pm 25 b$ & $522 \pm 61 a$ \\
\hline Fine root length ( $\leq 0.05 \mathrm{~mm}$ in diameter) & $313 \pm 33 b$ & $347 \pm 38 b$ & $321 \pm 28 b$ & $461 \pm 44 a$ \\
\hline Thick root length (>0.05 $\mathrm{mm}$ in diameter) & $47 \pm 8 a$ & $63 \pm 18 a$ & $41 \pm 9 a$ & $61 \pm 17 a$ \\
\hline Total root surface area $\left(\mathrm{cm}^{2}\right)$ & $35.95 \pm 5.56 b$ & $42.57 \pm 7.20 \mathrm{ab}$ & $37.88 \pm 2.55 b$ & $52.68 \pm 7.75 a$ \\
\hline Total root volume $\left(\mathrm{cm}^{3}\right)$ & $0.285 \pm 0.058 b$ & $0.300 \pm 0.019 b$ & $0.316 \pm 0.041 a b$ & $0.423 \pm 0.076$ \\
\hline Average diameter (mm) & $0.316 \pm 0.017 a$ & $0.328 \pm 0.033 a$ & $0.334 \pm 0.025 a$ & $0.320 \pm 0.012$ \\
\hline Number of root tips & $1378 \pm 148 b$ & $1735 \pm 331 a$ & $1353 \pm 139 b$ & $1662 \pm 160 \mathrm{ab}$ \\
\hline
\end{tabular}

Note: ${ }^{a}$ the value for each trait is determined per plant. Data are means \pm SD $(n=3)$, and different letters indicate significant differences using the least significant difference multiple range test $(p<0.05)$

that of CS. Under Pi deficiency, the shoot P content of KN199 was higher than that of CS. So, KN199 had higher PAE both under $+\mathrm{Pi}$ and $-\mathrm{Pi}$ conditions. Under limited Pi supply, high Pi level in shoots is a higher priority than that in roots in KN199. Pi deficiency increased the shoot and root PUE (Biomass production per unit of $\mathrm{P}$ ) in both cultivars. The increase in shoots was more significant in CS (4.7 folds) than that in KN199 (2.8 folds). Besides, the variation in roots between the two cultivars was not significant. Thus, the low-Pi tolerant cultivar KN199 had higher PAE and preferentially maintained high total Pi concentration in shoots in response to Pi deficiency.
The genes related to miR399-mediated signaling were differentially regulated in shoots, but not in roots

To elucidate the molecular mechanism of the favorable adaptations in root traits and P uptake in the low-Pi tolerant cultivar KN199, we first analyzed the gene expression related to the miR399-mediated signaling (PHR1IPS1-miR399-UBC24/PHO2 signaling cascade), TaPHR1, TaIPS1, TaSPX3, and TaPHO2 (Fig. 3). PHR1, an MYB-type transcription factor, was a critical factor in regulating the expression of several downstream phosphate starvation responsive genes [40]. Under Pi deficiency, the TaPHR1 abundance in shoots showed opposite changes between the two cultivars, both not

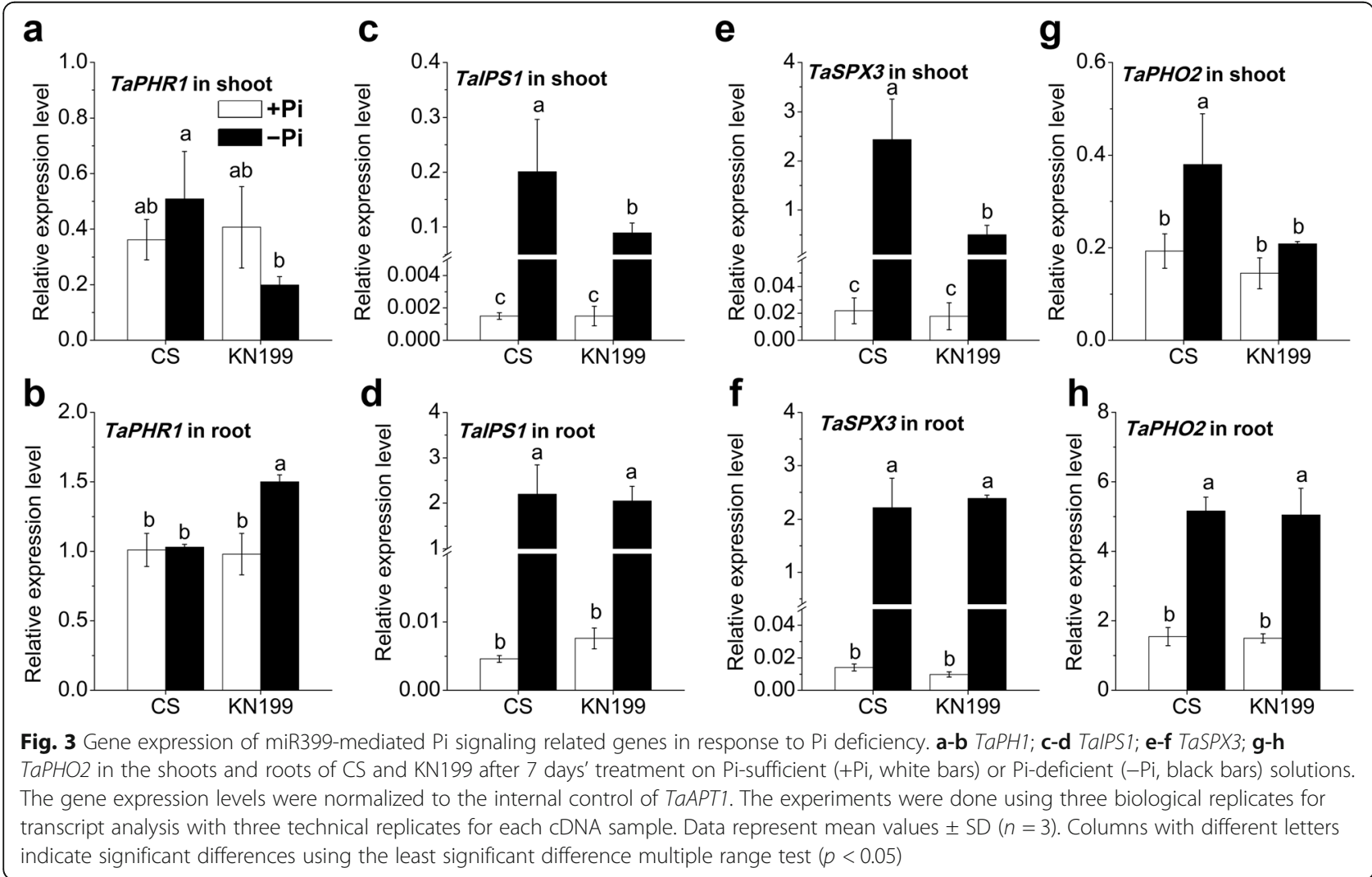


significantly (Fig. 3, a). The TaPHR1 abundance in the roots was significantly increased by $\mathrm{Pi}$ deficiency in KN199, but which did not change in CS (Fig. 3, b). Unlike the small changes of TaPHR1, the expression levels of TaIPS1 and TaSPX3 in shoots and roots were all dramatically increased by Pi deficiency in the two cultivars (Fig. 3, c-f). Remarkably, the up-regulation in the shoots of KN199 was much lower than these in CS, but they almost had no significant differences between the two cultivars. The expression levels of $\mathrm{TaPHO} 2$ in roots were much higher than those in shoots. Under - Pi condition, the TaPHO2 abundances in CS significantly increased in shoots and roots, but which in KN199 significantly increased only in roots (Fig. 3, g and h). In short, these key genes related to miR399-mediated signaling were much greater induced in the shoots of CS than those in KN199, while these genes in roots had no significant differential expression between the two cultivars. These differential regulations in shoots between the two cultivars were consistent with the changes in total $\mathrm{P}$ and $\mathrm{Pi}$ concentration. The Pi deficiency-induced variations in shoot total $\mathrm{P}$ and $\mathrm{Pi}$ concentrations were larger than that in roots. Under P deficiency, KN199 could maintain higher shoot total P and Pi concentrations than CS. These suggested that the different adaptations in the root architecture of the two cultivars was probably not contributed to the differential regulation of the miR399-mediated signaling pathway.

\section{The genes related to hormone-mediated signaling were} differentially regulated in roots

Besides miR399-mediated signaling, many hormones have been reported to involve in Pi starvation signaling pathways, such as auxin, ethylene, GA, and JA. Changes in $\mathrm{Pi}$ availability alter hormone production, sensitivity, and transport, and then affect RSA $[15,21]$. The transcriptional levels of genes associated with hormone metabolism and transport were tested in the roots of the two cultivars (Fig. 4). Tryptophan decarboxylase (TDC) [41] and PIN-FORMED auxin efflux transporters (PIN) [42] are key proteins involved in auxin biosynthesis and transport, respectively. The TaTDC and TaPIN9
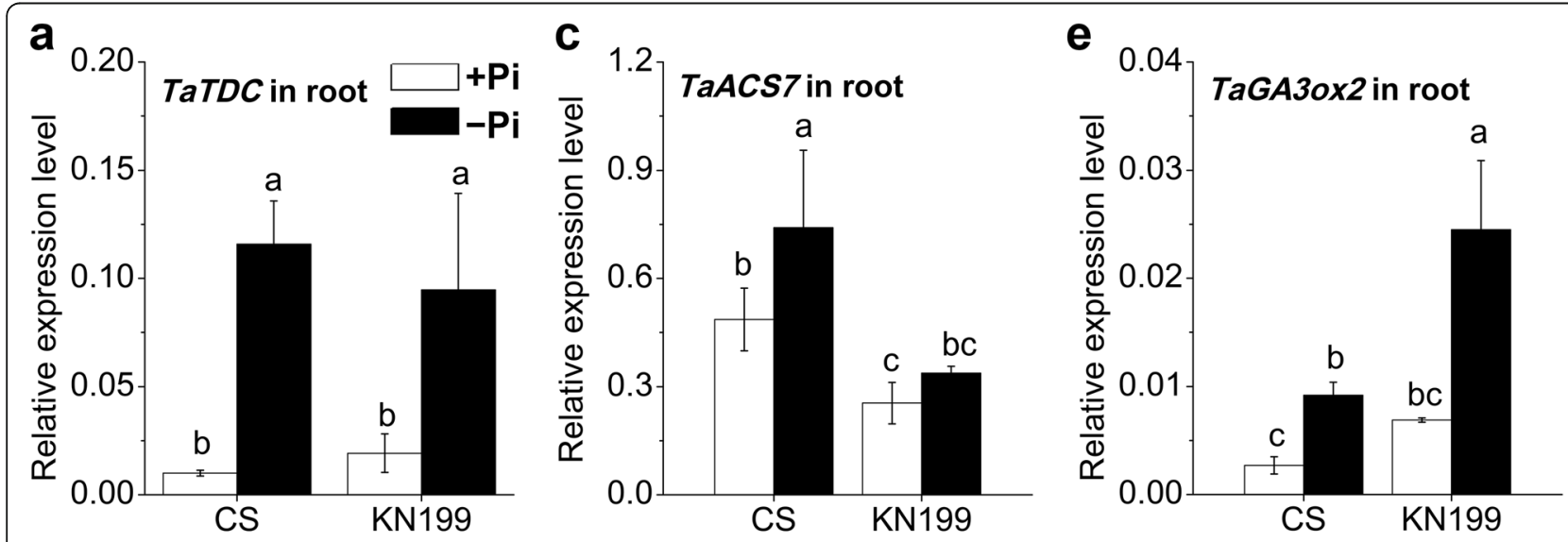

b
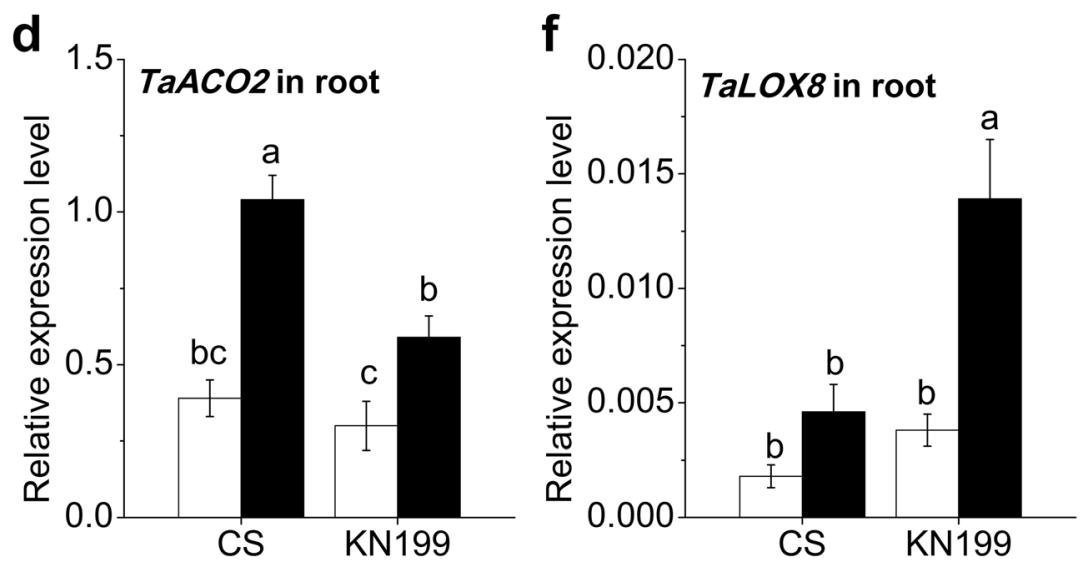

Fig. 4 Gene expression of hormone-mediated signaling related genes in response to Pi deficiency. a TaTDC; b TaPIN9; c TaACS7; d TaACO2; e TaGA30X2; f TaLOX8 in the roots of CS and KN199 after 7 days' treatment on Pi-sufficient (+Pi, white bars) or Pi-deficient (-Pi, black bars) solution. Data represent mean values \pm SD $(n=3)$, and different letters indicate differences significantly $(p<0.05)$ using the least significant difference multiple range test 
abundances were significantly increased by Pi deficiency in roots (Fig. 4, a and b), however, there was no significant difference between the two cultivars in this regard. The transcript abundances of genes involved in ethylene synthesis, 1-aminocyclopropane-1-carboxylic acid synthase 7 (ACS7) and 1-aminocyclopropane-1-carboxylic acid oxidase 2 (ACO2) [43], were also significantly increased under Pi stress, except TaACS7 in KN199 (Fig. 4, c and d). The increase of the TaACS7 abundance in the roots of KN199 was slight. Besides, the up-regulation of TaACO2 in KN199 was lower than that in CS. Compared with CS, the induction of ethylene biosynthesis by Pi deficiency inhibited in KN199. GA 3-oxidase (GA3ox) and lipoxygenase (LOX) are essential proteins involved in the GA and JA biosynthesis, respectively $[44,45]$. The expression levels of TaGA3ox2 and TaLOX8 were low in roots. However, the TaGA3ox 2 and TaLOX8 abundances were all significantly induced in the roots of the two cultivars (Fig. 4, e and f). Although these two genes were increased about $2-3$ folds by Pi deficiency in the two cultivars, the expression levels in KN199 were about two-fold higher than these in CS. Phosphate deficiency significantly induced the biosynthesis of these hormones in roots, and the genes associated with ethylene, GA, and JA had differential regulation between the two cultivars. These indicated that the hormone-mediated signaling is probably involved in the different changes of the Pi deficiency-induced root traits.

\section{The genes associated with root development were differentially regulated in roots}

Further, the expression of several genes related to root development was determined in the two cultivars. E2Frelated (E2F) transcription factors regulated root cell cycle entry and DNA synthesis [46]. A moderate level of $T a E 2 f$ was detected both in roots and shoots of the two cultivars (Fig. 5, a and b). Under Pi deficiency, the TaE2f abundance in the roots of CS was significantly increased, while which was slightly decreased in KN199. In shoots, the TaE2f abundances were both down-regulated in the two cultivars. The SOMATIC EMBRYOGENESIS RECEPTOR KINASE1 (SERK1) is a member of the Leurich repeat, receptor-like kinase protein family, and plays a critical role in root differentiation [47]. The expression

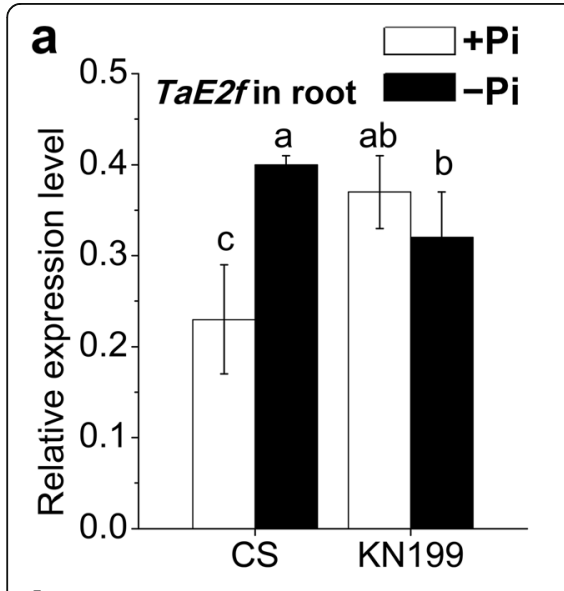

b
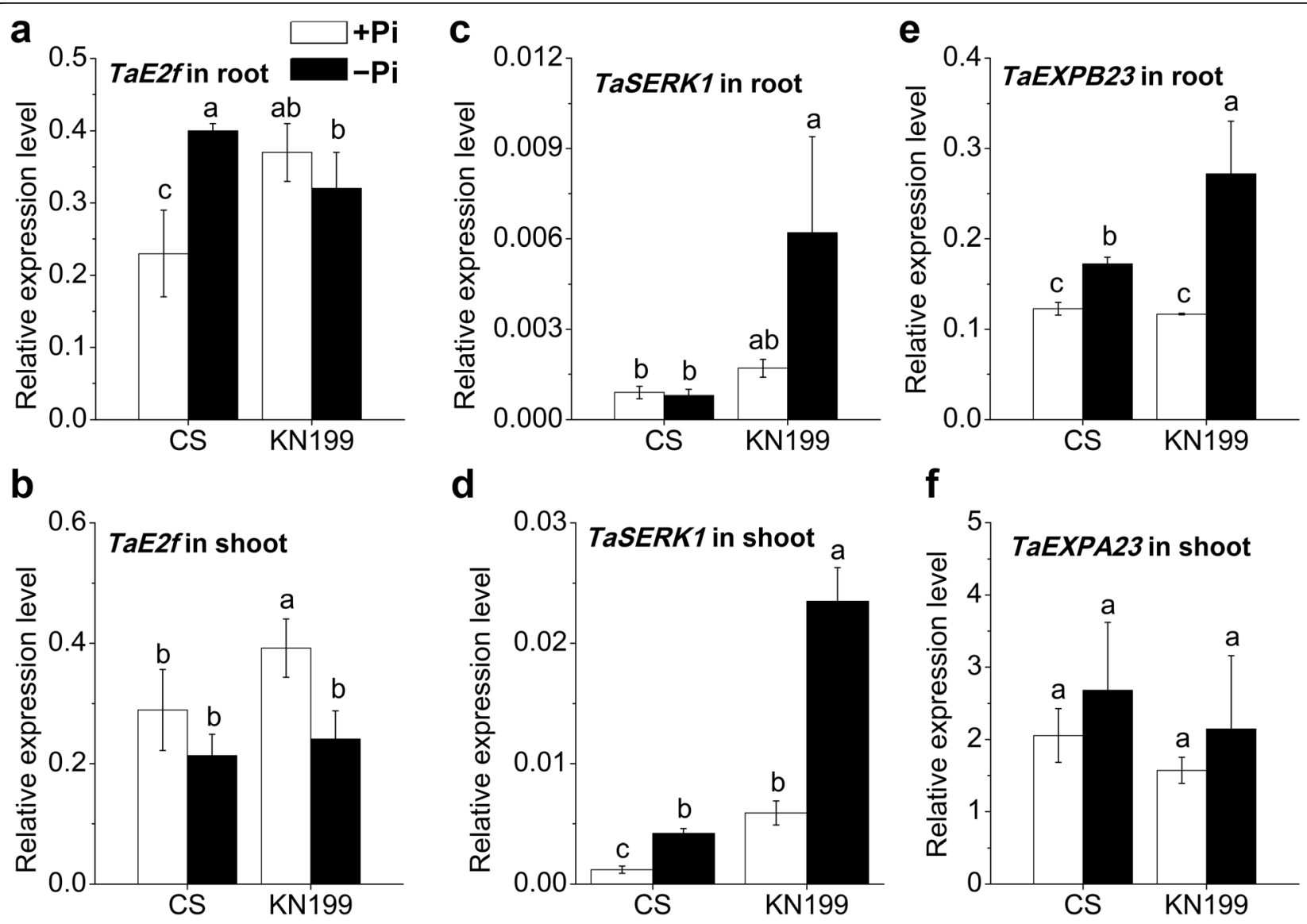

Fig. 5 Gene expression of root development related genes in response to Pi deficiency. a-b TaE2f; c-d TaSERK1; e-f TaEXPB23 in the roots and shoots of CS and KN199 after 7 days' treatment on Pi-sufficient (+Pi, white bars) or Pi-deficient (-Pi, black bars) solution. Data represent mean values $\pm \mathrm{SD}(n=3)$, and different letters indicate significant differences $(p<0.05)$ using the least significant difference multiple range test 
levels of TaSERK1 were relatively low in the roots and shoots of two cultivars (Fig. 5, c and d). Under Pi deficiency, the TaSERK1 abundances were remarkably upregulated about 7-folds in roots of KN199, while which had no obvious change in CS. In shoots, the TaSERK1 abundances were both up-regulated in the two cultivars. And the expression level in KN199 was much higher than that in CS. Expansins are involved in plant development, especially root development [48]. The TaEXPB23 abundance in roots both increased under Pi deficiency in the two cultivars (Fig. 5, e). The increased fold in KN199 was also much higher than that in CS. The TaEXPB23 abundances were slightly induced in shoots, and they were no differences between the two cultivars (Fig. 5, f). So, these genes associated with root development were mainly differentially regulated by Pi deficiency between the roots of two cultivars. It was consistent with different Pi deficiency responses in root traits.

The expression levels of the phosphate transporter 1 (PHT1) genes were greatly induced in the roots of KN199 The PHT1 family genes mediate Pi uptake and remobilization in wheat [49]. We detected the expression levels of TaPHT1.1/1.9 and TaPHT1.3 under +Pi and Pi conditions. The expression of TaPHT1.1/1.9 gene was root specific. The expression levels of TaPHT1.1/1.9 were moderate, and which of TaPHT1.3 were high (Fig. 6, a and b). Under Pi deficiency, the TaPHT1.1/1.9 and TaPHT1.3/1.4 abundances were significantly upregulated in two cultivars. The TaPHT1.1/1.9 expression level in KN199 was higher than that in CS. Likely, the up-regulation of TaPHT1.3/1.4 in KN199 was much stronger than that in CS. The higher induction of these
PHT1 genes in the roots of KN199 probably contributed to the uptake of more $\mathrm{Pi}$, maintaining the high level of total $\mathrm{P}$ and $\mathrm{Pi}$ concentration in shoots under $\mathrm{Pi}$ deficiency.

\section{Accumulations of organic acids and amino acids enhanced in KN199 under Pi deficiency}

The metabolic changes in roots were simultaneously investigated using gas chromatography-mass spectrometry (GC-MS). A total of 98 metabolite features were detected in the roots of the two cultivars. However, only 44 metabolites were identified (Additional file 1: Fig. S1 and Additional file 2: Table S1). To find the different performances of the two cultivars in response to Pi deficiency, heatmap analysis of the 44 identified metabolites was conducted. Phosphate starvation changed the abundances of root metabolites, and more remarkable changes were observed in the roots of KN199 (Fig. 7 and Additional file 3: Table S2). Twenty-five metabolites in roots were significantly changed by Pi stress in the two cultivars, including ten organic acids, four amino acids, and 11 other compounds. Principle component analysis (PCA) was performed based on these 25 metabolites (Fig. 8 and Additional file 4: Table S3). PC1 and PC2 accounted for approximately $73.8 \%$ of the total variation. Under $+\mathrm{Pi}$ condition, the samples of the two cultivars could not separate well, while they separated well under -Pi condition (Fig. 8, a). The samples of KN199 under $+\mathrm{Pi}$ and $-\mathrm{Pi}$ conditions could separate; however, the samples of CS did not separate. It indicated that the Pi deficiency caused more significant changes in KN199 than CS in root metabolites. The main metabolites contributing to the PC1 included threonine, glycine, Lvaline, fumaric acid, etc. (Fig. 8, b).
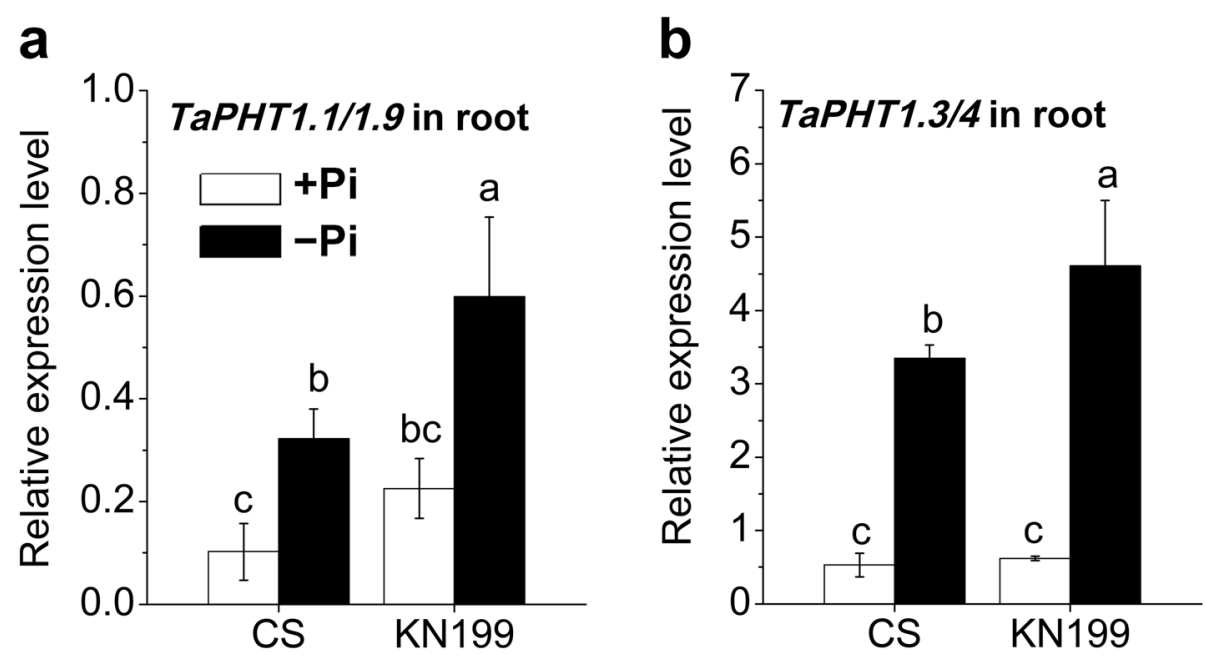

Fig. 6 Gene expression of the TaPHT1s genes in response to Pi deficiency. TaPHT1.1/1.9 (a) and TaPHT1.3/4 (b) in the roots of CS and KN199 after 7 days' treatment on Pi-sufficient (+Pi, white bars) or Pi-deficient ( $-\mathrm{Pi}$, black bars) solution. Data represent mean values $\pm \mathrm{SD}(n=3)$, and different letters indicate significant differences $(p<0.05)$ using the least significant difference multiple range test 


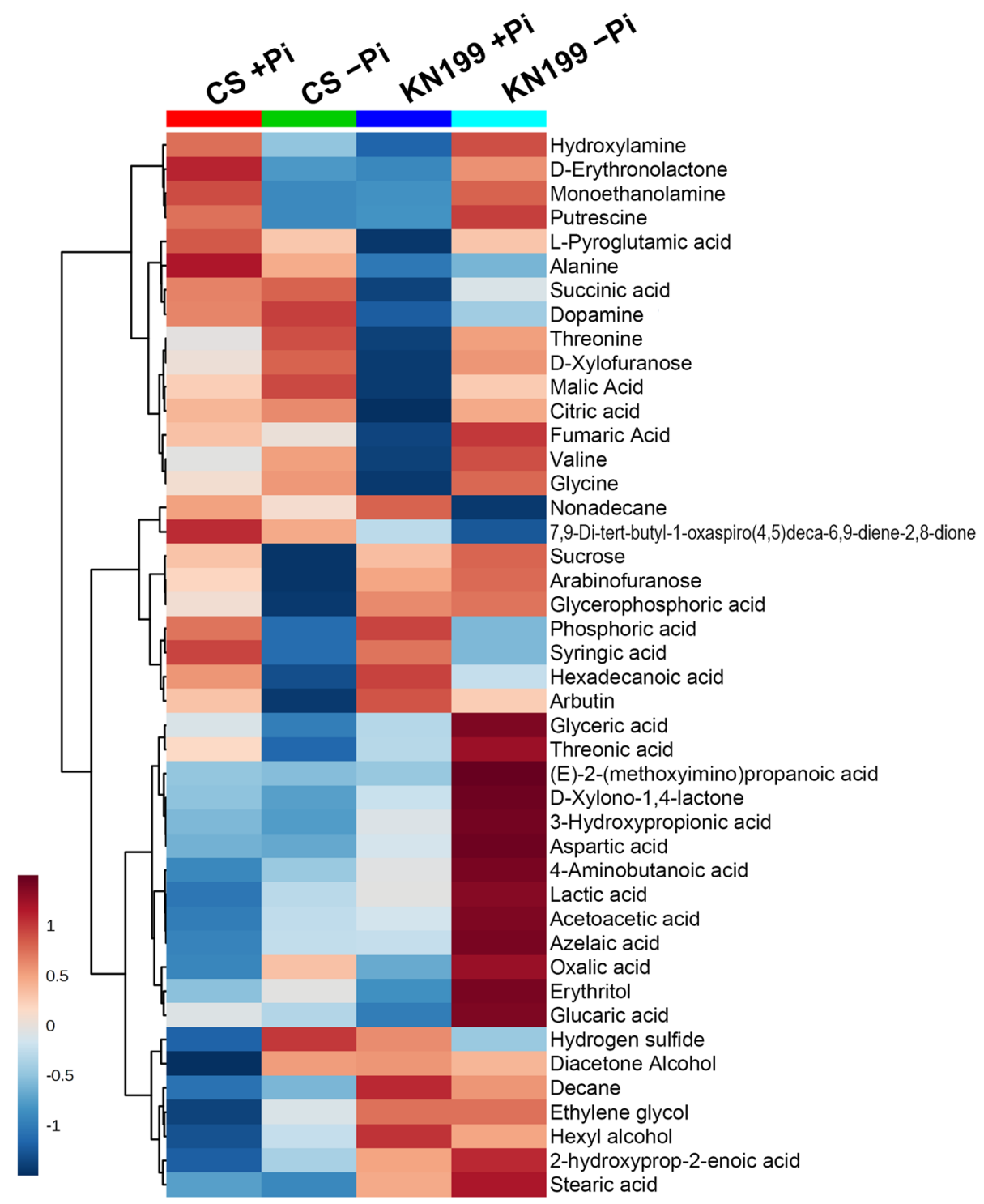

Fig. 7 Heatmap and hierarchical cluster analysis for the 44 detected metabolites. The two cultivars, CS and KN199, were detected under Pisufficient or Pi-deficient conditions $(n=4)$

Under Pi deficiency, only three and six metabolites in the roots of CS showed significant up-regulated and down-regulated, respectively (Fig. 9). Meanwhile, 18 metabolites significantly accumulated in the roots of KN199. Only the phosphoric acid concentration severely decreased under $-\mathrm{Pi}$ condition. Overall, Pi deficiency caused greater increases of metabolites in the roots of KN199 than CS. In particular, the accumulations of amino acids were pronounced. KN199 accumulated higher contents of threonine, glycine, valine, and LPyroglutamic acid in response to Pi deficiency (Fig. 9). However, in CS, only the valine concentration showed a significant increase. Similarly, the accumulations of organic acids also significantly increased in the roots of KN199. The concentrations of fumaric acid, oxalic acid, citric acid, malic acid, and lactic acid were increased 1.60-6.93 folds by Pi deficiency. However, the concentrations of these metabolites were not significantly changed in the roots of CS, except lactic acid. Besides, the arabinofuranose, arbutin, D-erythronolactone, glycerophosphoric acid, and sucrose concentrations were significantly decreased by Pi deficiency in CS. While these metabolites did not significantly change in KN199. Thus, the accumulation of primary metabolites, amino acids and organic acids, was remarkably enhanced in KN199 by Pi deficiency.

\section{Discussion}

Pi deficiency causes a severe reduction in crop growth and yield. The development of wheat cultivars with low- 

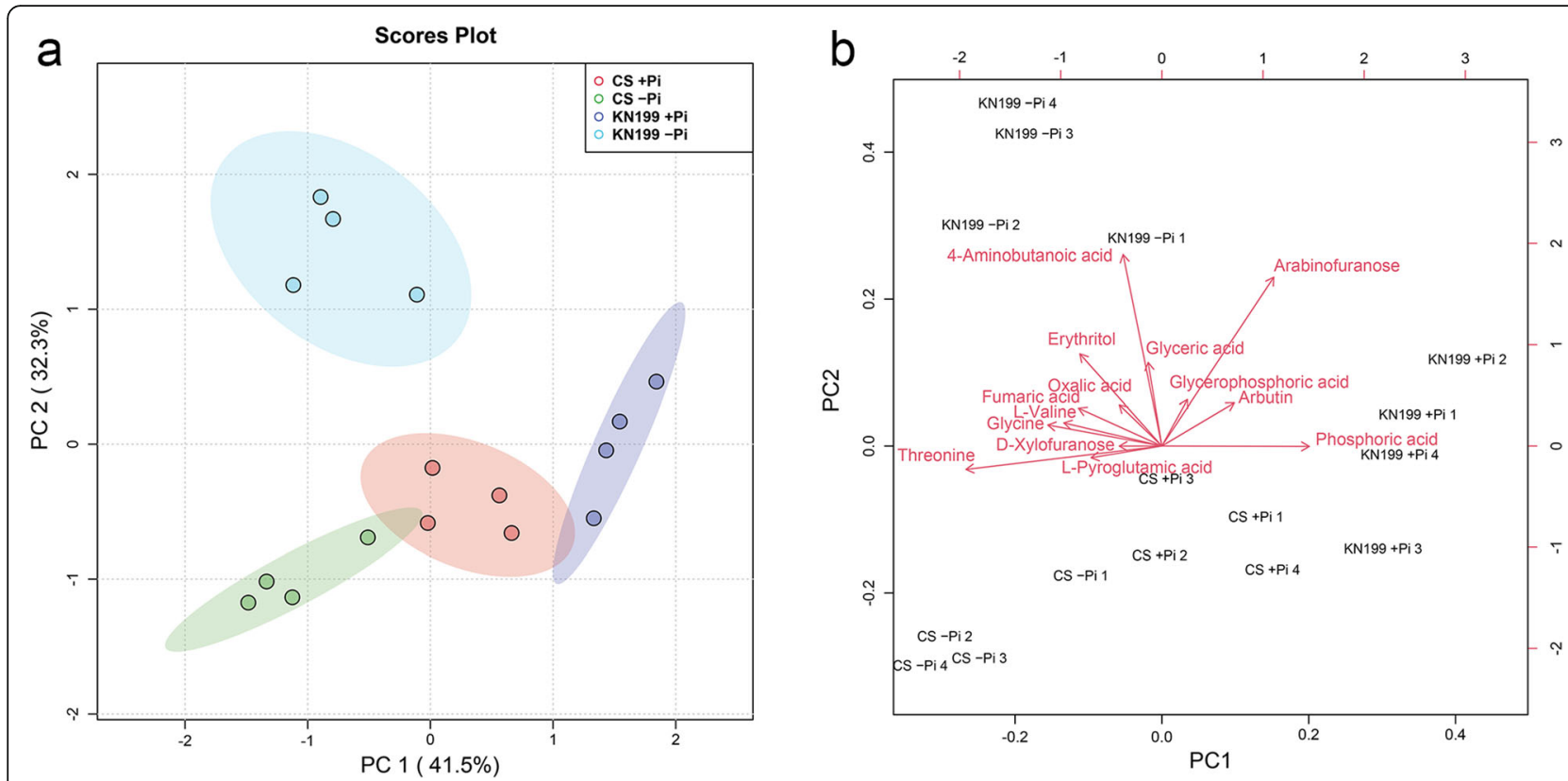

Fig. 8 Principle component analysis (PCA) scores plot (a) and the corresponding loading plot (b) of root metabolome variation among the two cultivars based upon four biological replicates. PC1: the first principal component; PC2: the second principal component. The PCA scores plot distinguishes the metabolic profiles of the two cultivars under $+\mathrm{Pi}$ and - Pi conditions. The main metabolites contributing to the PC1 and PC2 are labeled

Pi tolerance and high-Pi efficiency is thus important for optimal fertilizer use, food security, and agricultural sustainability. The wheat cultivar KN199 showed high stress tolerance and production under low $\mathrm{P}$ input in longterm field experiments [38]. Coincidently, KN199 displayed low-Pi tolerance in the seedling stage under hydroponic condition. By comparing with low-Pi sensitive cultivar CS, we revealed the adaption and the relevant molecular mechanisms of low-Pi tolerant cultivar KN199 in this study.

\section{The low-Pi tolerance of KN199 contributed to great root architecture adaptation}

High-yield cultivars were mostly obtained by selecting the above-ground organs, whereas the below-ground roots are generally neglected. Undoubtedly, root traits played vital roles in anchorage, water and nutrient uptake, environmental stress tolerance, and productivity [6]. In our study, the most obvious phenotypic variation in response to Pi deficiency between the two wheat cultivars was the modification in roots. Under Pi deficiency, the total root length (fine roots) and root biomass greatly increased in KN199 with greater total surface area and total root volume. This adaptation in root traits, especially fine roots, was crucial for absorbing more immobile $\mathrm{Pi}$ in soil. Fine roots have high plasticity and the potential to change their growth and development to adjust to changing environments [50]. Global analysis of fine root production demonstrated that fine root production also increased with soil $\mathrm{P}$ in natural conditions, particularly at $\mathrm{P}<300 \mathrm{mg} \mathrm{kg}^{-1}$ [51]. However, its responses differed among plant species, and soil types. In common herbaceous crops, species with thinner roots tended to increase root branching intensity and first-order root length and explore soil P mainly by developing more intensely branched fine roots and higher specific root length [12]. A study based on 215 wheat genotypes demonstrated that genotypes with a greater ratio of seminal lateral root length to seminal axis root length under reduced $\mathrm{P}$ condition had a higher root $\mathrm{P}$ concentration [52]. Compared to low-P sensitive lines, the tolerant barley lines revealed greater root plasticity in the terms of lateral root length under low-P stress [53]. The adaptation manner in wheat was different from some other plants. In A. thaliana, the primary root length reduced under the limiting Pi condition, but the formation of lateral roots and root hairs increased [10]. In common bean, total root length and lateral root number greatly reduced under Pi deficiency [54]. The root traits observed in wheat were more similar to those in barley. After 10 days of Pi deficiency, the barely seedlings had more lateral roots, but shorter primary roots [27]. The selection and breeding of high PUE cultivars by root performance was blocked by the difficulty in observing root traits. Ren et al. reported quantitative trait locus pyramiding based on hydroponic culture for root traits provided practical information for development of wheat varieties with large and deep root system and 


\begin{tabular}{|c|c|c|c|}
\hline Metabolite name & CS & KN199 & $\log _{2}{ }^{(-P i /+P i)}$ \\
\hline \multicolumn{3}{|l|}{ Organic acids } & 5 \\
\hline Acetoacetic acid & 0.58 & $1.08^{*}$ & 4 \\
\hline Citric acid & 0.19 & $0.74^{*}$ & 3 \\
\hline Fumaric acid & -0.14 & $2.79^{* * *}$ & 2 \\
\hline Lactic acid & $0.36^{*}$ & $0.68^{*}$ & 1 \\
\hline Malic acid & 0.35 & $0.80^{\star *}$ & 0 \\
\hline Oxalic acid & ND & $1.60^{* \star *}$ & -1 \\
\hline \multicolumn{3}{|l|}{ Amino acids } & -2 \\
\hline 4-Aminobutanoic acid & 1.02 & $3.11^{* *}$ & -3 \\
\hline L-Pyroglutamic acid & -0.59 & $1.98^{* *}$ & -4 \\
\hline Glycine & 0.69 & $3.07^{* * *}$ & -5 \\
\hline Valine & $0.60 *$ & $2.72^{* *}$ & \\
\hline Threonine & 2.10 & $3.89^{*}$ & \\
\hline \multicolumn{3}{|l|}{ Other compounds } & \\
\hline Arabinofuranose & $-3.89^{* * *}$ & 0.66 & \\
\hline Arbutin & $-2.07^{*}$ & -0.53 & \\
\hline Azelaic acid & 0.03 & $0.55^{\star *}$ & \\
\hline D-Erythronolactone & $-0.96^{*}$ & 1.14 & \\
\hline Diacetone alcohol & $1.61^{* *}$ & 0.08 & \\
\hline D-Xylofuranose & 0.39 & $0.97^{* * *}$ & \\
\hline D-Xylono-1,4-lactone & -0.20 & $1.18^{*}$ & \\
\hline Erythritol & 0.72 & $3.00^{* * *}$ & \\
\hline Glyceric acid & -0.91 & $1.76^{* *}$ & \\
\hline Glycerophosphoric acid & $-0.92^{*}$ & 0.08 & \\
\hline Monoethanolamine & -0.46 & $0.70^{*}$ & \\
\hline Phosphoric acid & $-3.46^{* * *}$ & $-2.88^{* * *}$ & \\
\hline Stearic acid & 0.01 & $0.19^{*}$ & \\
\hline Sucrose & $-0.66^{*}$ & 0.17 & \\
\hline
\end{tabular}

Fig. 9 Heat map of metabolite contents in the roots which significant changes in either of cultivar under Pi deficiency. Variations in metabolites are represented by fold change calculated using formula $\log _{2}{ }^{(-P i /+P i)}$. The parts in bold indicate the different categories of metabolites. Asterisks indicate significant differences between $P$ treatments by the student's $t$-test $(n=4),{ }^{*} p<0.05,{ }^{* *} p<0.01$, and ${ }^{* * *} p<0.001$, respectively

efficient P uptake [55]. However, the effect of Pi deficiency on root development is complex, speciesspecific, and cultivar dependent [5], breeding of $\mathrm{Pi}$ deficiency-tolerant wheat cultivars is still challenging. The exploration of molecular regulation and key components in response to low Pi response could provide crucial clues for genetic engineering approaches to enhance PAE.
Molecular regulation for the root adaptation in response to Pi deficiency

The expression of Pi-starvation response genes revealed the possible regulatory mechanisms for the low-Pi tolerance of KN199. The genes related to the miR399mediated signaling pathway had no significant differences between the roots of two cultivars, while the genes involved in hormones (ethylene, GA, and JA) 
biosynthesis and root development were differentially expressed between the two cultivars. Ethylene synthesis had implicated in changing the RSA in response to Pi deficiency in plants. In Arabidopsis, inhibition of ethylene production decreased the elongation of roots in low $\mathrm{Pi}$ conditions [24]. In common bean, ethylene production per $g$ dry matter in roots was significantly higher under Pi-deficient conditions with reduction of root mass and lateral root density [54]. In wheat, the genes involved in ethylene biosynthesis were significantly increased under Pi deficiency. However, the increase of TaACS7 was not obvious in KN199 under Pi deficiency. The inhibition of ethylene production may increase the root elongation in KN199. GA stimulated root growth by promoting the destruction of the repressors, a family of nuclear growth-repressing DELLA proteins [56]. In Arabidopsis, Pi starvation caused a decrease in the level of bioactive GA and related genes involved in GA metabolism, triggering the inhibition of root and shoot growth and accumulation of anthocyanin [23]. While in wheat, the TaGA3ox2 gene involved in GA biosynthesis was both induced in two cultivars, which enhanced the active of GA, and then increased root biomass under $\mathrm{Pi}$ deficiency. Transcriptome analyses had demonstrated that genes in hormone biosynthesis and responses were regulated under Pi deficiency $[25,57,58]$. However, evidence for the specificity and direct association of certain hormones needs further studies, particularly in wheat.

Besides, the genes associated with root development, TaE2f, TaSERK1, and TaEXPB23, were also differentially regulated in roots between the two cultivars. In Arabidopsis, transcription factor $E 2 F C$ negatively regulates lateral root formation [46]. The transgenic plant with reduced $E 2 f c$ mRNA levels developed organs with more but smaller cells and increased proliferative activity. The expression regulation of TaE2f in response to $\mathrm{Pi}$ deficiency was consistent with root morphological changes in the two cultivars. SERKs control somatic embryogenesis and root formation in plants [47, 59]. Overexpression of TaSERK1 in Arabidopsis increased plant height, root length, and even larger silique size and increased seed yield [60]. Expansins may also play roles in root architecture in response to Pi deficiency. The up-regulation of expansin genes in Stylosanthes participated in root growth under low $\mathrm{Pi}$ condition [61]. GmEXPB2, a vegetative $\beta$-expansin gene, encodes a secretory protein on the cell wall and is highly induced by Pi starvation in soybean [62]. Overexpressing GmEXPB2 in Arabidopsis increased root cell division and elongation, enhanced plant growth, and $\mathrm{P}$ uptake. Consistently, the significantly increased expression of TaSERK1 and TaEXPB2 in roots of KN199 contributed to the enhanced root development under Pi deficiency.
Molecular regulation for the $\mathrm{Pi}$ uptake under $\mathrm{Pi}$ deficiency The total $\mathrm{P}$ and $\mathrm{Pi}$ concentrations could preferentially maintain at the higher level in shoots of KN199 than that in CS. Results showed that the expression of genes involved in the miR399-mediated signaling pathway was differentially expressed in shoots of the two cultivars. miR399 is specifically response to Pi stress as a systemic signal $[15,17]$. It directs the cleavage of PHO2 mRNA encoding a ubiquitin conjugating $\mathrm{E} 2$ enzyme. $\mathrm{PHO} 2$ regulates Pi transport through ubiquitin-mediated protein degradation. An Arabidopsis pho2 mutant overaccumulated Pi in leaves under Pi stress [17]. The expression level of $\mathrm{TaPHO} 2$ significantly increased in shoots of CS under Pi deficiency, while the abundance of TaPHO2 in the shoots of KN199 did not significantly change. Thus, the inhibition of TaPHO2 may contribute to the high Pi concentration in the shoots of KN199. Similarly, the up-regulation of TaIPS1 and TaSPX3 was also inhibited in the shoots of KN199. In A. thaliana, overexpression of AtIPS1 increased the accumulation of the miR399 target PHO2 mRNA, resulting in reducing shoot $\mathrm{Pi}$ content [19]. In barely, The P-acquisitionefficient cultivar had a low abundance of IPS1 [20]. These results indicate that low expression of IPS genes resulted in highly efficient uptake and $\mathrm{Pi}$ accumulation in shoots. SPXs mainly reported as a negative regulator in Arabidopsis and rice in response to Pi stress [63]. In rice, nuclear-localized SPX1 and SPX2 were Pidependent inhibitors for the activity of OsPHR2 by inhibiting its binding to the PHR1-binding sequence, P1BS motif [64]. Compared with wide type plants, Osspx1 and Osspx 2 single mutants had a significantly higher Pi concentration in high Pi conditions. Consistent with the above studies, the high Pi concentration in the shoot of KN199 partly contributed to the weak expression of TaIPS1 and TaSPX3. Besides, the genes TaPHT1.1/1.9 and TaPHT1.3 were stronger induced in KN199 under Pi stress, which absorb and transport more Pi. Campos et al. revealed that the higher PAE of the wheat cultivar Crac was associated with an improved IPS1-miR399$\mathrm{PHO} 2$ signalling in roots through a fine-tuning modulation of PHO2 activity [65]. In sum, the regulation in miR399-mediated signaling pathway, together with the induction of TaPHT1 genes, kept KN199 maintain high total P and Pi concentration under Pi deficiency.

\section{Accumulations of the primary metabolites revealed the accelerated carbon and nitrogen flow under Pi stress}

For in-depth analyzing the changes in roots, nonbiased metabolite profiling using GC-MS revealed that about $56 \%$ of identified metabolites differentially accumulated between two wheat cultivars. Most of the primary metabolites detected in the roots increased in response to $\mathrm{Pi}$ deficiency. And more remarkable changes were 
observed in KN199 than these in CS. The primary metabolic adaptations in response to Pi deficiency were in agreement with previous analyses in common bean [29]. Most of amino acids, nitrogen compounds, some organic acids, polyols, and sugars were increased under Pi deficiency, only eight metabolites were decreased in the roots of common bean. Strikingly, organic acids of the TCA cycle were significantly induced under Pi deficiency in the roots of the wheat cultivars, especially in KN199 (Fig. 10). The result was consistent with that observed in the roots of wheat, tomato, chickpea, and white lupin [66]. The malic acid, citric acid, and malonic acid tested in these plants were almost all significantly increased. In barley, the levels of malate, citrate, and $\alpha$-ketoglutarate were also increased under ten days of Pi deficiency treatment [27]. But after 17 days of Pi deficiency treatment, these organic acids in the barley roots were slightly reduced, indicating the shortage in carbohydrate supply in severely Pi-deficient plants. Some distinct changes were detected in some other plants. In rice, the concentration of lactic acid in roots was increased, while malic acid and citrate were decreased under Pi deficiency [26]. In common bean, different organic acids had different variations. Succinic acid and malic acid were increased and decreased under Pi deficiency, respectively [29]. The abundances of organic acids exhibited large variation between the low-Pi tolerant and low-Pi sensitive maize cultivars [28]. Thus, it appears that metabolic changes in the TCA cycle in response to Pi deficiency differ among plant species and plant cultivars. The increased accumulation of primary metabolites in KN199 indicated that the acceleration of carbon flow in adapt to moderate low-Pi stress of 7 days in wheat.

In many plants, root secrets organic acids into the rhizosphere to enhance $\mathrm{Pi}$ solubilization and release fixed P in soils [5]. However, in our study, we tried to collect the root exudates of the two wheat cultivars in response to Pi deficiency. However, the secreted malic

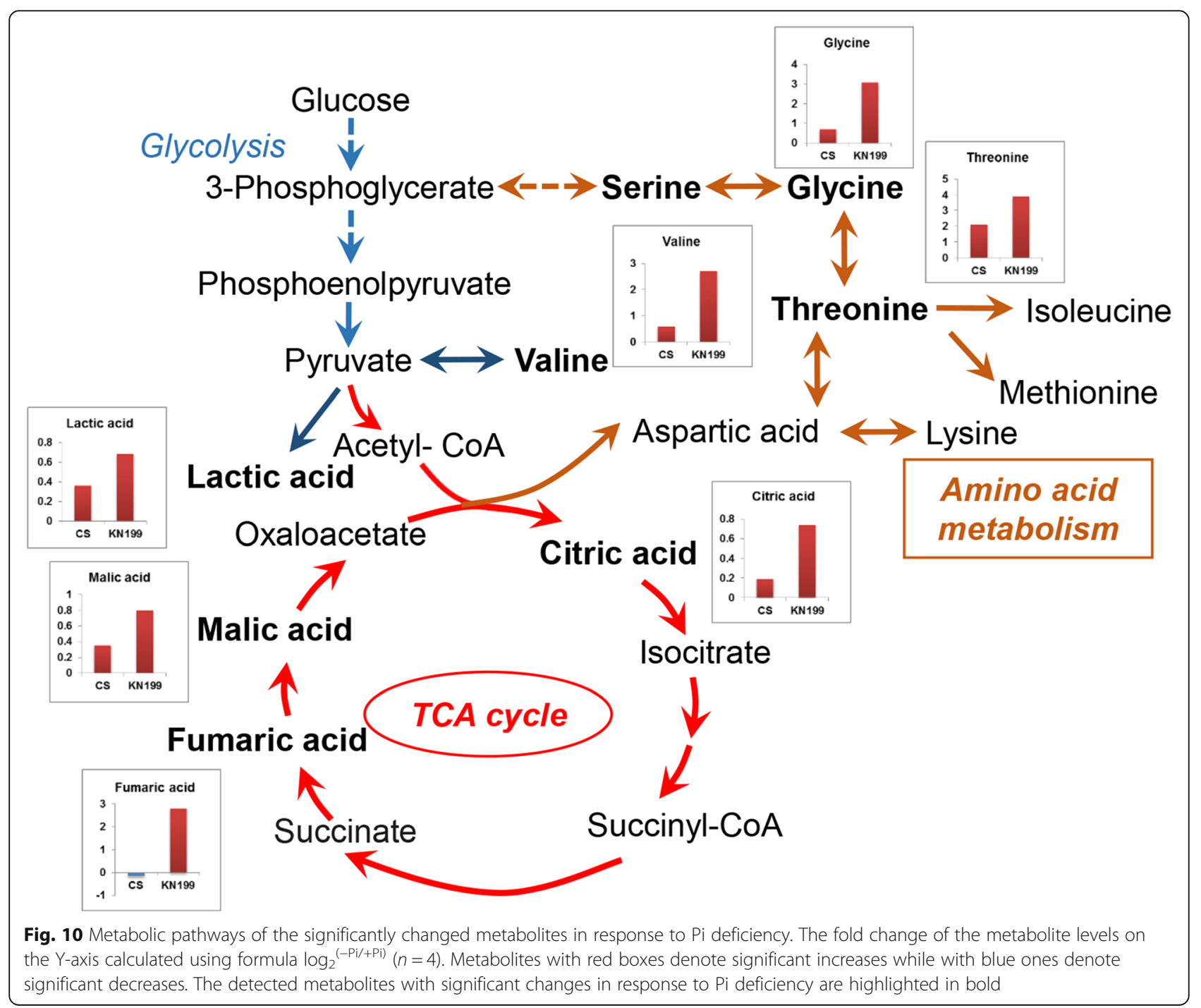


acid, lactic acid, acetic acid, citric acid, fumaric acid, and succinic acid were extremely low. Neumann et al. reported the increased secretion of malic acid, citric acid, and malonic acid secreted in chickpea and white lupin, but not in wheat under P stress [66]. In wheat, only malic acid and low concentration of oxalic acid were detected in tested nine organic acids. Our results revealed that little root exudation was induced by Pi deficiency in wheat, although organic acids highly accumulated in the roots.

Several amino acids accumulated in the two wheat cultivars under Pi stress and the increase was also much more pronounced in the Pi-tolerant cultivar KN199 (Fig. 9). Consistent with these observation in some other plants, Pi deficiency induced the accumulation of most amino acids detected in wheat. In the roots of common bean and soybean, most of the amino acids increased under Pi stress, such as threonine, arginine, lysine, and serine $[29,30]$. This accumulation of amino acids in roots possibly due to increased protein degradation and repressed protein synthesis under Pi stress. In the roots of severely Pi-deficiency barely, the amino acids involved in ammonium metabolism, glutamine, asparagine, and putrescine, were sharply increased, leading to an increased level of ammonium and alteration in ammonium assimilation [27]. The intracellular accumulation of amino acids could also be used as the source or intermediates of carbon and nitrogen metabolism under Pi deficiency. Especially, valine and threonine, which share the synthetic pathway with branched chain amino acids, displayed the most significant change. These amino acids were common responses under abiotic stresses would be an alternative electron donor for mitochondrial electron transport and an important alternative respiratory substrate $[67,68]$.

\section{Conclusions}

In summary, our results demonstrated a suite of Pi deficiency responses ranging from root morphology, physiology, gene expression, and metabolites using low-Pi sensitive cultivar CS and low-Pi tolerant cultivar KN199. To adapt to Pi deficiency environment, the KN199 developed more favorable root traits for P uptake, with larger root biomass and longer fine root length. These adaptations probably contributed to the regulation of key genes related to the ethylene, gibberellin, and jasmonates-mediated signaling, root development, and $\mathrm{Pi}$ transporters in roots. The total $\mathrm{P}$ and Pi concentrations could preferentially keep at a higher level in shoots, which regulated by genes related to miR399-mediated signaling. The organic acids in TCA cycle and branched chain amino acids also accumulated as the preferred storage metabolites in the roots of KN199 for enhanced carbon and nitrogen metabolism. The understanding of mechanisms through the two contrasting wheat cultivars (the wild and cultivated variety) would help to design more effective breeding and genetic engineering strategies to produce highly PAE crop.

\section{Methods}

\section{Wheat cultivars and growth conditions}

Bread wheat (Triticum aestivum L.) cultivar KN199 and CS were used in this study. Seeds of these two cultivars were provided by Professor Xiuying Kong from Chinese Academy of Agricultural Sciences, China. CS was the model wheat, which widely studied [69]. KN199 was derived from a cross between Kn9204 (a 1RS/1BL translocated and derivative of wheat Thinopyrum ponticum partial amphiploid) and Shi4185 (developed by Institute of Genetics and Developmental Biology, Chinese Academy of Sciences) [37], and has been commercialized now. No special permissions are necessary to collect and use plant materials. All the plant materials were grown in compliance with the legislation of China.

The healthy seeds of two cultivars (CS and KN199) were surface-sterilized with $10 \% \mathrm{H}_{2} \mathrm{O}_{2}$ and then germinated on filter paper saturated with distilled water in darkness at $25^{\circ} \mathrm{C}$ for 1 day. The seeds were transplanted into a plastic net suspended on a plastic pot $(1.25 \mathrm{~L})$ filled with $0.5 \mathrm{mM} \mathrm{CaCl}$ solution ( $\mathrm{pH} 4.5$ ) for 3 days. And then, the seedlings with similar growth parameters were selected and transplanted into 1/4 modified Hoagland solution. Each $1.25 \mathrm{~L}$ black pot had five seedlings. To study the $\mathrm{Pi}$ deficiency response, the 12-day-old seedlings were grown on Pi-sufficient $(250 \mu \mathrm{M} \mathrm{Pi},+\mathrm{Pi})$ or Pi-deficient $(0 \mu \mathrm{M} \mathrm{Pi},-\mathrm{Pi}) 1 / 4$ modified Hoagland nutrient solution for 7 days [70]. The Pi-sufficient nutrient solution contained $250 \mu \mathrm{M} \mathrm{KH}{ }_{2} \mathrm{PO}_{4}$, and the Pi-deficient nutrient solution did not contain $\mathrm{KH}_{2} \mathrm{PO}_{4}$ with an additional $250 \mu \mathrm{M} \mathrm{KCl}$. The modified $1 / 4$ Hoagland solution was composed of $(\mu \mathrm{M}): \mathrm{Ca} \quad\left(\mathrm{NO}_{3}\right)_{2} \cdot 4 \mathrm{H}_{2} \mathrm{O}$ (2000), $\mathrm{MgSO}_{4} \cdot 7 \mathrm{H}_{2} \mathrm{O}$ (650), $\mathrm{KH}_{2} \mathrm{PO}_{4}$ (250), $\mathrm{K}_{2} \mathrm{SO}_{4}$ (750), $\mathrm{KCl}$ (100), $\quad \mathrm{MnSO}_{4} \cdot \quad \mathrm{H}_{2} \mathrm{O} \quad(10), \quad \mathrm{CuSO}_{4} \cdot 5 \mathrm{H}_{2} \mathrm{O} \quad(0.1)$, $\mathrm{ZnSO}_{4} \cdot 7 \mathrm{H}_{2} \mathrm{O}(1), \mathrm{H}_{3} \mathrm{BO}_{3}(1),\left(\mathrm{NH}_{4}\right)_{6} \mathrm{MoO}_{24} \cdot 4 \mathrm{H}_{2} \mathrm{O}(0.05)$, and Fe (III)-EDTA (40) [70]. The pH was adjusted to 6.0. The solutions were replenished regularly at threeday intervals. The hydroponic experiment was performed at the Institute of Soil Science, Chinese Academy of Sciences, Nanjing, China. The seedlings were grown in a temperature-controlled growth chamber with a 14$\mathrm{h} / 26^{\circ} \mathrm{C}$ day and a $10-\mathrm{h} / 23^{\circ} \mathrm{C}$ night cycle, a light intensity of $300 \mu \mathrm{mol} \mathrm{m}^{-2} \mathrm{~s}^{-1}$, and a relative humidity of $60 \%$. At least three biological replicates were performed for each treatment and sampling.

\section{Soluble Pi concentration and total P concentration}

Shoots and roots of seedling were sampled respectively, weighed, and homogenized in liquid nitrogen to 
determine the soluble Pi concentration. Phosphate was extracted with $8 \mathrm{~mL}$ of $5 \%(\mathrm{v} / \mathrm{v})$ sulphuric acid $(5 \mathrm{M})$ solution. The supernatants were obtained by centrifugation at $12000 \mathrm{~g}$ for $15 \mathrm{~min}$ for Pi determination. To determine the total $\mathrm{P}$ concentration, the oven dried samples were ground to powders and digested with $5 \mathrm{~mL} \mathrm{H}_{2} \mathrm{SO}_{4}$ for $3 \mathrm{~h}$ at $150^{\circ} \mathrm{C}$. Meantime, $\mathrm{H}_{2} \mathrm{O}_{2}$ was added to make the samples properly digest. The total $\mathrm{P}$ and soluble $\mathrm{Pi}$ concentrations were measured using the molybdate blue-colorimetric method [71]. The diluted samples ( $\mathrm{pH}$ adjusted) were mixed with $15 \%(\mathrm{w} / \mathrm{v})$ fresh ascorbic acid dissolved in ammonium molybdate (pH 5.0) and then incubated at $37^{\circ} \mathrm{C}$ for $30 \mathrm{~min}$. The absorbance at $650 \mathrm{~nm}$ was recorded. The $\mathrm{Pi}$ and total $\mathrm{P}$ concentrations were calculated using FW and DW normalization, respectively.

\section{Global root morphology analysis}

To characterize the global root morphology, the harvested roots were dispersed on a clear perspex tray with water and scanned using a root system scanner (EPSON Expression 1600, Seiko EPSON Corp., Japan). The images were analyzed using WinRHIZO software (WIN MAC, Regent Instruments Inc., Canada; http://www. regentinstruments.com/). WinRHIZO output included total root length per plant in centimeter $(\mathrm{cm})$, fine root length $(\leq 0.5 \mathrm{~mm}$ in diameter), thick root length $(>0.5$ $\mathrm{mm}$ in diameter) [7], total root surface area in $\mathrm{cm}^{2}$, average diameter in millimeter $(\mathrm{mm})$, total root volume per plant in $\mathrm{cm}^{3}$, and the number of tips.

\section{Gene expression analysis}

Total RNA was extracted from homogenized frozen shoots or roots $(50 \mathrm{mg})$ according to the operations manual supplied by Plant RNA Kit (TianGen, OSRM610) and convert into cDNAs using Prime Script reverse transcriptase (Toyobo, FSQ-101). The quality and quantity of RNA were assessed using agarose gel electrophoresis and the NanoDrop 2000 (Thermo Fisher Scientific, USA). The quantitative real-time PCR reactions were performed in a $10 \mu \mathrm{L}$ reaction volume containing $0.01 \mu \mathrm{g}$ of cDNA, $0.2 \mu \mathrm{M}$ of each primer, and $5.0 \mu \mathrm{L}$ of SYBR Green Realtime PCR Master Mix (Toyobo, QPK201). Three technical replicates were conducted for each cDNA sample. Three biological replicates were used for transcript analysis. The wheat adenine phosphoribosyltransferase (TaAPT1) gene was used as housekeeping gene [70]. The relative expression levels of genes were calculated according to the $2{ }^{-\Delta \Delta} \mathrm{Ct}$ method [72]. The primer sequences for the tested genes are listed in Additional file 5: Table S4.

\section{GC-MS analysis of intracellular metabolites in roots}

The metabolite extraction and derivatization were performed as described by Ganie et al. [28]. The homogenized frozen roots $(100 \mathrm{mg})$ were extracted with pre-cooled solvents, isopropanol: acetonitrile: water (3:3: 2) and chloroform: water (1:2). The methanol/water phase was dried by vacuum centrifugation (Concentrator Plus, Eppendorf, Germany) overnight. After carbonyl moieties were protected by methoximation, the acidic protons were derivatized with $70 \mu \mathrm{L} \mathrm{N}$-methyl-N-trimethylsilyl trifluoroacetamide (Sigma-Aldrich Co., USA) at $37^{\circ} \mathrm{C}$ for $90 \mathrm{~min}$. The trimethylsilyl samples were separated and analyzed using the GC-MS system (GC: Varian CP-3800, MS: Saturn 2200, USA) according to the method of Ganie [28]. Mass spectra were recorded from $\mathrm{m} / \mathrm{z} 35$ to 600 for trimethylsilyl derivatization. Compounds were identified by comparing them with the reference compounds in MainLib or Wiley Registry8e (Additional file 1: Fig. S1 and Additional file 2: Table S1). Mass spectral matching was manually supervised, and matches were accepted with thresholds of match 700. The areas of the identified metabolites were analyzed using MetaboAnalyst 4.0 online (https://www. metaboanalyst.ca/MetaboAnalyst/faces/home.xhtml)

[73]. The remaining missing values were estimated using the Singular Value Decomposition method [74]. Log normalization was used for data transformation. Features were removed with $>51 \%$ missing values. The identified metabolites were comprehensively compared using the PCA and Heatmap analysis. The fold-change of metabolite between control and treatment was transformed by a logarithmic base of 2 .

\section{Statistical analysis}

Data represent means \pm SD of at least three biological replicates. Student' $t$-test or two-way analysis of variance (ANOVA) was conducted between two cultivars under $+\mathrm{Pi}$ and $-\mathrm{Pi}$ conditions and followed by the least significant difference (LSD) multiple range test $(p<0.05)$ using IBM SPSS statistical software (version 22.0.0.0) for statistical analysis.

\section{Abbreviations \\ +Pi/-Pi: Sufficient/deficient-inorganic phosphate; ACO2: 1- \\ Aminocyclopropane-1-carboxylic acid oxidase 2; ACS7: 1- \\ Aminocyclopropane-1-carboxylic acid synthase 7; DW: Dry weight; E2F: E2F- related; FW: Fresh weight; GA: Gibberellin; GA3ox: GA 3-oxidase; GC-MS: Gas chromatography-mass spectrometry; JAs: Jasmonates; LOX: Lipoxygenase; \\ P: Phosphorus; PAE: Phosphate acquisition efficiency; PCA: Principle component analysis; Pi: inorganic phosphate; PHO2: PHOSPHATE2; PHR1: Phosphate starvation response 1; PUE: Phosphate utilization efficiency; RSA: Root system architecture; SERK1: SOMATIC EMBRYOGENESIS RECEPTOR KINASE1; TCA: Tricarboxylic acid}

\section{Supplementary Information}

The online version contains supplementary material available at https://doi. org/10.1186/s12870-021-03164-6.

Additional file 1.

Additional file 2 . 


\section{Additional file 3. \\ Additional file 4. \\ Additional file 5.}

\section{Acknowledgements}

We are grateful to Professor Xiuying Kong (Chinese Academy of Agricultural Sciences, China) for kindly providing the seeds of wheat cultivars. We also thank Doctor Hatem Rouached (French National Institute for Agricultural Research, France) and Doctor Jorge Rodríguez-Celma (John Innes Centre, UK) for valuable suggestions and comments.

\section{Authors' contributions}

P.L. conceived and designed the research. L.Z. performed the experiments and data analyses. L.Z. drafted the manuscript. P.L., Y.G.H., R.F.S., and M.R.K. revised the manuscript. All authors read and approved the final manuscript.

\section{Funding}

This study was supported by the National Key Research and Development Program of China (No. 2016YFD0200308), the Project of Priority and Key Areas, Institute of Soil Science, Chinese Academy of Sciences (No. ISSASIP1605 and ISSASIP1640), and the Open Project Program of State Key Laboratory of Crop Stress Biology for Arid Areas (No. CSBAA2020006). The funding body played no role in the design of the study and collection, analysis, and interpretation of the data and in writing the manuscript.

\section{Availability of data and materials}

All data generated or analyzed during this study are included in this published article and its supplementary information files.

\section{Declarations}

\section{Ethics approval and consent to participate}

Not applicable.

\section{Consent for publication}

Not applicable.

\section{Competing interests}

The authors declare that they have no competing interests.

\section{Author details}

${ }^{1}$ State Key Laboratory of Soil and Sustainable Agriculture, Institute of Soil Science, Chinese Academy of Sciences, Nanjing 210008, China. ${ }^{2}$ University of Chinese Academy of Sciences, Beijing 100049, China. ${ }^{3}$ State Key Laboratory of Crop Stress Biology for Arid Areas, College of Agronomy, Northwest A\&F University, Yangling 712100, China.

Received: 16 April 2021 Accepted: 4 August 2021

Published online: 19 August 2021

\section{References}

1. Raghothama K. Phosphate acquisition. Annu Rev Plant Physiol Plant Mol Biol. 1999;50:665-93 https://doi.org/10.1146/annurev.arplant.50.1.665.

2. Schachtman DP, Reid RJ, Ayling SM. Phosphorus uptake by plants: from soil to cell. Plant Physiol. 1998;116(2):447-53 https://doi.org/10.1104/pp.116.2.44 7.

3. Ma J, He P, Xu X, He W, Liu Y, Yang F, et al. Temporal and spatial changes in soil available phosphorus in China (1990-2012). Field Crop Res. 2016;192: 13-20 https://doi.org/10.1016/j.fcr.2016.04.006.

4. Ramaekers L, Remans R, Rao IM, Blair MW, Vanderleyden J. Strategies for improving phosphorus acquisition efficiency of crop plants. Field Crop Res. 2010;117(2-3):169-76 https://doi.org/10.1016/j.fcr.2010.03.001.

5. López-Arredondo DL, Leyva-González MA, González-Morales SI, López-Bucio J, Herrera-Estrella L. Phosphate nutrition: improving low-phosphate tolerance in crops. Annu Rev Plant Biol. 2014(65):23.1-29. https://doi.org/1 0.1146/annurev-arplant-050213-035949.

6. Lynch J. Root architecture and plant productivity. Plant Physiol. 1995;109(1): 7-13 https://doi.org/10.1104/pp.109.1.7.

7. Gu D, Zhen F, Hannaway DB, Zhu Y, Liu L, Cao W, et al. Quantitative classification of rice (Oryza sativa L.) root length and diameter using image analysis. PLoS ONE. 2017;12(1):e0169968. https://doi.org/10.1371/journal. pone.0169968.

8. Yavitt JB, Harms KE, Garcia MN, Mirabello MJ, Wright SJ. Soil fertility and fine root dynamics in response to 4 years of nutrient $(N, P, K)$ fertilization in a lowland tropical moist forest, Panama. Austral Ecology. 2011;36(4):433-45 https://doi.org/10.1111/j.1442-9993.2010.02157.x.

9. Lugli LF, Rosa JS, Andersen KM, Di Ponzio R, Almeida RV, Pires M, et al. Rapid responses of root traits and productivity to phosphorus and cation additions in a tropical lowland forest in Amazonia. New Phytol. 2021;230(1): 116-28 https://doi.org/10.1111/nph.17154.

10. Sánchez-Calderón L, López-Bucio J, Chacón-López A, Cruz-Ramírez A, NietoJacobo F, Dubrovsky JG, et al. Phosphate starvation induces a determinate developmental program in the roots of Arabidopsis thaliana. Plant Cell Physiol. 2005;46(1):174-84 https://doi.org/10.1093/pcp/pci011.

11. Vejchasarn P, Lynch JP, Brown KM. Genetic variability in phosphorus responses of rice root phenotypes. Rice. 2016;9(1):29 https://doi.org/10.11 86/s12284-016-0102-9.

12. Wen Z, Li H, Shen Q, Tang X, Xiong C, Li H, et al. Tradeoffs among root morphology, exudation and mycorrhizal symbioses for phosphorusacquisition strategies of 16 crop species. New Phytol. 2019;223(2):882-95 https://doi.org/10.1111/nph.15833.

13. Heppell J, Talboys P, Payvandi S, Zygalakis KC, Fliege J, Withers PJ, et al. How changing root system architecture can help tackle a reduction in soil phosphate (P) levels for better plant P acquisition. Plant Cell Environ. 2015; 38(1):118-28 https://doi.org/10.1111/pce.12376.

14. da Silva A, Bruno IP, Franzini VI, Marcante NC, Benitiz L, Muraoka T. Phosphorus uptake efficiency, root morphology and architecture in Brazilian wheat cultivars. J Radioanal Nucl Ch. 2015;307(2):1055-63 https://doi.org/1 0.1007/s10967-015-4282-3.

15. Chiou TJ, Lin SI. Signaling network in sensing phosphate availability in plants. Annu Rev Plant Biol. 2011;62:185-206 https://doi.org/10.1146/a nnurev-arplant-042110-103849.

16. Zhang Z, Liao H, Lucas WJ. Molecular mechanisms underlying phosphate sensing, signaling, and adaptation in plants. J Integr Plant Biol. 2014;56(3): 192-220 https://doi.org/10.1111/jipb.12163.

17. Bari R, Datt Pant B, Stitt M, Scheible WR. PHO2, microRNA399, and PHR1 define a phosphate-signaling pathway in plants. Plant Physiol. 2006;141(3): 988-99 https://doi.org/10.1104/pp.106.079707.

18. Zhou Z, Wang Z, Lv Q, Shi J, Zhong Y, Wu P, et al. SPX proteins regulate pi homeostasis and signaling in different subcellular level. Plant Signal Behav. 2015;10(9):e1061163 https://doi.org/10.1080/15592324.2015.1061163.

19. Franco-Zorrilla JM, Valli A, Todesco M, Mateos I, Puga MI, Rubio-Somoza I, et al. Target mimicry provides a new mechanism for regulation of microRNA activity. Nat Genet. 2007;39(8):1033-7 https://doi.org/10.1038/ng2 079.

20. Huang CY, Shirley N, Genc Y, Shi BJ, Langridge P. Phosphate utilization efficiency correlates with expression of low-affinity phosphate transporters and noncoding RNA, IPS1, in barley. Plant Physiol. 2011;156(3):1217-29 https://doi.org/10.1104/pp.111.178459.

21. Nacry P, Canivenc G, Muller B, Azmi A, Van Onckelen H, Rossignol M, et al. A role for auxin redistribution in the responses of the root system architecture to phosphate starvation in Arabidopsis. Plant Physiol. 2005;138(4):2061-74 https://doi.org/10.1104/pp.105.060061.

22. Nagarajan VK, Smith AP. Ethylene's role in phosphate starvation signaling: more than just a root growth regulator. Plant Cell Physiol. 2012;53(2):277-86 https://doi.org/10.1093/pcp/pcr186.

23. Jiang C, Gao X, Liao L, Harberd NP, Fu X. Phosphate starvation root architecture and anthocyanin accumulation responses are modulated by the gibberellin-DELLA signaling pathway in Arabidopsis. Plant Physiol. 2007; 145(4):1460-70 https://doi.org/10.1104/pp.107.103788.

24. Ma Z, Baskin TI, Brown KM, Lynch JP. Regulation of root elongation under phosphorus stress involves changes in ethylene responsiveness. Plant Physiol. 2003;131(3):1381-90 https://doi.org/10.1104/pp.012161.

25. Misson J, Raghothama KG, Jain A, Jouhet J, Block MA, Bligny R, et al. A genome-wide transcriptional analysis using Arabidopsis thaliana Affymetrix gene chips determined plant responses to phosphate deprivation. Proc Natl Acad Sci U S A. 2005;102(33):11934-9 https://doi.org/10.1073/pnas.0505266102.

26. Tawaraya K, Horie R, Saito A, Shinano T, Wagatsuma T, Saito K, et al. Metabolite profiling of shoot extracts, root extracts, and root exudates of rice plant under phosphorus deficiency. J Plant Nutr. 2013;36(7):1138-59 https://doi.org/10.1080/01904167.2013.780613. 
27. Huang CY, Roessner U, Eickmeier I, Genc Y, Callahan DL, Shirley N, et al. Metabolite profiling reveals distinct changes in carbon and nitrogen metabolism in phosphate-deficient barley plants (Hordeum vulgare L.). Plant Cell Physiol. 2008;49(5):691-703 https://doi.org/10.1093/pcp/pcn044.

28. Ganie AH, Ahmad A, Pandey R, Aref IM, Yousuf PY, Ahmad S, et al. Metabolite profiling of low-P tolerant and low-P sensitive maize genotypes under phosphorus starvation and restoration conditions. PLoS One. 2015; 10(6):e0129520 https://doi.org/10.1371/journal.pone.0129520.

29. Hernández G, Ramírez M, Valdés-López O, Tesfaye M, Graham MA, Czechowski T, et al. Phosphorus stress in common bean: root transcript and metabolic responses. Plant Physiol. 2007;144(2):752-67 https://doi.org/10.11 04/pp.107.096958.

30. Tawaraya K, Horie R, Shinano T, Wagatsuma T, Saito K, Oikawa A. Metabolite profiling of soybean root exudates under phosphorus deficiency. Soil Sci Plant Nutr. 2014;60(5):679-94 https://doi.org/10.1080/00380768.2014.945390.

31. Wang F, Deng M, Xu J, Zhu X, Mao C. Molecular mechanisms of phosphate transport and signaling in higher plants. Semin Cell Dev Biol. 2018;74:11422 https://doi.org/10.1016/j.semcdb.2017.06.013.

32. Chiou TJ, Aung K, Lin SI, Wu CC, Chiang SF, Su CL. Regulation of phosphate homeostasis by MicroRNA in Arabidopsis. Plant Cell. 2006;18(2):412-21 https://doi.org/10.1105/tpc.105.038943.

33. Manske GGB, Ortiz-Monasterio Jl, van Ginkel M, González RM, Fischer RA, Rajaram S, et al. Importance of P uptake efficiency versus P utilization for wheat yield in acid and calcareous soils in Mexico. Eur J Agron. 2001;14(4): 261-74 https://doi.org/10.1016/S1161-0301(00)00099-X.

34. Li H, Liu J, Li G, Shen J, Bergstrom L, Zhang F. Past, present, and future use of phosphorus in Chinese agriculture and its influence on phosphorus losses. Ambio. 2015;44(Suppl 2):S274-85 https://doi.org/10.1007/s13280-0150633-0.

35. Conley DJ, Paerl HW, Howarth RW, Boesch DF, Seitzinger SP, Havens KE, et al. Ecology. Controlling eutrophication: nitrogen and phosphorus. Science. 2009;323(5917):1014-5 https://doi.org/10.1126/science.1167755.

36. Ma WQ, Ma L, Li JH, Wang FH, Sisák I, Zhang FS. Phosphorus flows and use efficiencies in production and consumption of wheat, rice, and maize in China. Chemosphere. 2011;84(6):814-21 https://doi.org/10.1016/j. chemosphere.2011.04.055.

37. Zhang W, Wang J, Jun J, Wang ZG, An DG, Zhang XQ, et al. Development of "Kn199" new winter wheat variety and its cultivation in China. Chin J EcoAgric. 2011;19(5):1215-9.

38. Zhao H, Zhang W, Wang J, Ji J, Wang ZG, Li JM. Analysis of high and stable yield characteristics of "Kn199" winter wheat cultivar. Chin J Eco-Agric. 2011; 19(5):1220-8.

39. Quan-you L, Yi-ping T, Jian-hua S, Ji-yun L. Study on optimal sowing density and fertilizer application rate for cultivating high quality wheat Xiaoyan 54 in Beijing area. Acta Bot Boreal-Occident Sin. 2001;21(3):592-496.

40. Rubio V, Linhares F, Solano R, Martín AC, Iglesias J, Leyva A, et al. A conserved MYB transcription factor involved in phosphate starvation signaling both in vascular plants and in unicellular algae. Genes Dev. 2001; 15(16):2122-33 http://www.genesdev.org/cgi/doi/10.1101/gad.204401.

41. Abu-Zaitoon YM. Phylogenetic analysis of putative genes involved in the tryptophan-dependent pathway of auxin biosynthesis in rice. Appl Biochem Biotechnol. 2014;172(5):2480-95 https://doi.org/10.1007/s12010-013-0710-4.

42. Zhou JJ, Luo J. The PIN-FORMED auxin efflux carriers in plants. Int J Mol Sci. 2018;19:2759 https://doi.org/10.3390/ijms19092759.

43. Larsen PB. Mechanisms of ethylene biosynthesis and response in plants. In: Guilfoyle T, Hagen G, editors. Plant Hormone Signalling. Essays in Biochemistry. 58. London: Portland Press Ltd; 2015. p. 61-70. https://doi. org/10.1042/bse0580061.

44. Schaller A, Stintzi A. Enzymes in jasmonate biosynthesis - structure, function, regulation. Phytochemistry. 2009;70(13-14):1532-8 https://doi.org/10.1016/j. phytochem.2009.07.032.

45. Colebrook EH, Thomas SG, Phillips AL, Hedden P. The role of gibberellin signalling in plant responses to abiotic stress. J Exp Biol. 2014;217(Pt 1):6775 https://doi.org/10.1242/jeb.089938.

46. del Pozo JC, Diaz-Trivino S, Cisneros N, Gutierrez C. The balance between cell division and endoreplication depends on E2FC-DPB, transcription factors regulated by the ubiquitin-SCF ${ }^{\text {SKP2A }}$ pathway in Arabidopsis. Plant Cell. 2006;18(9):2224-35 https://doi.org/10.1105/tpc.105.039651.

47. Hecht V, Vielle-Calzada JP, Hartog MV, Schmidt EDL, Boutilier K, Grossniklaus $U$, et al. The Arabidopsis SOMATIC EMBRYOGENESIS RECEPTOR KINASE 1 gene is expressed in developing ovules and embryos and enhances embryogenic competence in culture. Plant Physiol. 2001;127(3):803-16 https://doi.org/1 $0.1104 /$ pp.010324

48. Han YY, Zhou S, Chen YH, Kong X, Xu Y, Wang W. The involvement of expansins in responses to phosphorus availability in wheat, and its potentials in improving phosphorus efficiency of plants. Plant Physiol Biochem. 2014;78:53-62 https://doi.org/10.1016/j.plaphy.2014.02.016.

49. Teng $W$, Zhao YY, Zhao XQ, He X, Ma WY, Deng Y, et al. Genome-wide identification, characterization, and expression analysis of PHT1 phosphate transporters in wheat. Front Plant Sci. 2017;8:543 https://doi.org/10.3389/ fpls.2017.00543.

50. Zobel RW, Kinraide TB, Baligar VC. Fine root diameters can change in response to changes in nutrient concentrations. Plant Soil. 2007;297(1-2): 243-54 https://doi.org/10.1007/s11104-007-9341-2.

51. Yuan ZY, Chen HY. A global analysis of fine root production as affected by soil nitrogen and phosphorus. Proc Biol Sci. 2012;279(1743):3796-802 https://doi.org/10.1098/rspb.2012.0955.

52. Zhao DY, Zheng SS, Naeem MK, Niu JQ, Wang N, Li ZJ, et al. Screening wheat genotypes for better performance on reduced phosphorus supply by comparing glasshouse experiments with field trials. Plant Soil. 2018;430(1-2): 349-60 https://doi.org/10.1007/s11104-018-3739-x.

53. Long L, Ma X, Ye L, Zeng J, Chen G, Zhang G. Root plasticity and pi recycling within plants contribute to low-P tolerance in Tibetan wild barley. BMC Plant Biol. 2019;19(1):341 https://doi.org/10.1186/s12870-019-1949-x.

54. Borch K, Bouma TJ, Lynch JP, Brown KM. Ethylene: a regulator of root architectural responses to soil phosphorus availability. Plant Cell Environ. 1999;22(4):425-31 https://doi.org/10.1046/j.1365-3040.1999.00405.X.

55. Ren Y, Qian Y, Xu Y, Zou C, Liu D, Zhao X, et al. Characterization of QTLs for root traits of wheat grown under different nitrogen and phosphorus supply levels. Front Plant Sci. 2017;8:2096 https://doi.org/10.3389/fpls.2017.02096.

56. Park J, Nguyen KT, Park E, Jeon JS, Choi G. DELLA proteins and their interacting RING finger proteins repress gibberellin responses by binding to the promoters of a subset of gibberellin-responsive genes in Arabidopsis. Plant Cell. 2013;25(3):927-43 https://doi.org/10.1105/tpc.112.108951.

57. Lan P, Li W, Schmidt W. 'Omics' approaches towards understanding plant phosphorus acquisition and use. In: Plaxton WC, Lambers H, editors. Annual Plant Reviews. Wiley, Ltd; 2015. p. 66-80. https://doi.org/10.1002/978111 8958841.ch3.

58. Rubio V, Bustos R, Irigoyen ML, Cardona-López X, Rojas-Triana M, Paz-Ares J. Plant hormones and nutrient signaling. Plant Mol Biol. 2009;69(4):361-73 https://doi.org/10.1007/s11103-008-9380-y.

59. Nolan KE, Kurdyukov S, Rose RJ. Expression of the SOMATIC EMBRYOGENESIS RECEPTOR-LIKE KINASE1 (SERK1) gene is associated with developmental change in the life cycle of the model legume Medicago truncatula. J Exp Bot. 2009;60(6):1759-71 https://doi.org/10.1093/jxb/erp046.

60. Singh A, Khurana P. Ectopic expression of Triticum aestivum SERK genes (TaSERKs) control plant growth and development in Arabidopsis. Sci Rep. 2017;7(1):12368 https://www.ncbi.n/m.nih.gov/pmc/articles/PMC5620050/.

61. Luo J, Liu Y, Zhang H, Wang J, Chen Z, Luo L, et al. Metabolic alterations provide insights into Stylosanthes roots responding to phosphorus deficiency. BMC Plant Biol. 2020;20(1):85 https://doi.org/10.1186/s12870-020-2283-z.

62. Guo W, Zhao J, Li X, Qin L, Yan X, Liao H. A soybean beta-expansin gene GMEXPB2 intrinsically involved in root system architecture responses to abiotic stresses. Plant J. 2011;66(3):541-52 https://doi.org/10.1111/j.1365-313 X.2011.04511.X.

63. Liu N, Shang W, Li C, Jia L, Wang X, Xing G, et al. Evolution of the SPX gene family in plants and its role in the response mechanism to phosphorus stress. Open Biol. 2018;8:170231 https://doi.org/10.1098/rsob.170231.

64. Wang Z, Ruan W, Shi J, Zhang L, Xiang D, Yang C, et al. Rice SPX1 and SPX2 inhibit phosphate starvation responses through interacting with PHR2 in a phosphate-dependent manner. Proc Natl Acad Sci U S A. 2014;111(41): 14953-8 https://doi.org/10.1073/pnas.1404680111.

65. Campos PMD, Cornejo P, Rial C, Borie F, Varela RM, Seguel A, et al. Phosphate acquisition efficiency in wheat is related to root:shoot ratio, strigolactone levels, and PHO2 regulation. J Exp Bot. 2019;70(20):5631-42 https://doi.org/10.1093/jxb/erz349.

66. Neumann G, Römheld V. Root excretion of carboxylic acids and protons in phosphorus-deficient plants. Plant Soil. 1999;211(1):121-30 https://doi.org/1 0.1023/A:1004380832118.

67. Obata T, Fernie AR. The use of metabolomics to dissect plant responses to abiotic stresses. Cell Mol Life Sci. 2012;69(19):3225-43 https://doi.org/10.1 007/s00018-012-1091-5. 
68. Araújo WL, Tohge T, Ishizaki K, Leaver CJ, Fernie AR. Protein degradation an alternative respiratory substrate for stressed plants. Trends Plant Sci. 2011;16(9):489-98 https://doi.org/10.1016/j.tplants.2011.05.008.

69. Ramírez-González RH, Borrill P, Lang D, Harrington SA, Brinton J, Venturini L, et al. The transcriptional landscape of polyploid wheat. Science. 2018; 361 (6403):eaar6089. https://doi.org/10.1126/science.aar6089.

70. Karim MR, Dong X, Zheng L, Shen R, Lan P. Can aluminum tolerant wheat cultivar perform better under phosphate deficient conditions? Int J Mol Sci. 2018;19(10):2964. https://doi.org/10.3390/ijms19102964.

71. Zheng L, Huang F, Narsai R, Wu J, Giraud E, He F, et al. Physiological and transcriptome analysis of iron and phosphorus interaction in rice seedlings. Plant Physiol. 2009;151(1):262-74 https://doi.org/10.1104/pp.109.141051.

72. Livak KJ, Schmittgen TD. Analysis of relative gene expression data using real-time quantitative PCR and the $2^{-\Delta \Delta C T}$ method. Methods. 2001;25(4): 402-8 https://doi.org/10.1006/meth.2001.1262

73. Chong J, Soufan O, Li C, Caraus I, Li S, Bourque G, et al. MetaboAnalyst 4.0: towards more transparent and integrative metabolomics analysis. Nucleic Acids Res. 2018;46(W1):W486-94 https://doi.org/10.1093/nar/gky310.

74. Stacklies W, Redestig H, Scholz M, Walther D, Selbig J. pcaMethods--a bioconductor package providing PCA methods for incomplete data. Bioinformatics. 2007;23(9):1164-7 https://doi.org/10.1093/bioinformatics/ btm069.

\section{Publisher's Note}

Springer Nature remains neutral with regard to jurisdictional claims in published maps and institutional affiliations.

Ready to submit your research? Choose BMC and benefit from:

- fast, convenient online submission

- thorough peer review by experienced researchers in your field

- rapid publication on acceptance

- support for research data, including large and complex data types

- gold Open Access which fosters wider collaboration and increased citations

- maximum visibility for your research: over $100 \mathrm{M}$ website views per year

At $\mathrm{BMC}$, research is always in progress.

Learn more biomedcentral.com/submissions 